\title{
Annual performance analysis and optimization of a solar tower aided coal-fired
}

\author{
power plant \\ Chao Li ${ }^{\mathrm{a}, \mathrm{b}}$, Rongrong Zhai ${ }^{\mathrm{a}, *}$, Yongping Yang ${ }^{\mathrm{a}}$, Kumar Patchigolla ${ }^{\mathrm{b}}$, John E. Oakey ${ }^{\mathrm{b}}$, Peter Turner ${ }^{\mathrm{b}}$

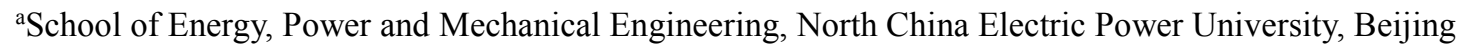 \\ 102206, China
}

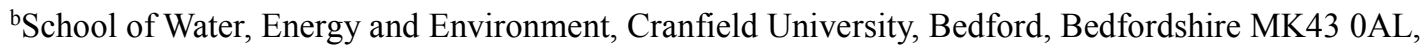
UK

${ }^{*}$ Corresponding author: Rongrong Zhai

E-mail:zhairongrong01@163.com

Tel.:+86-10-61772284; Fax: +86-10-61772284

\begin{abstract}
The integration of solar energy into coal-fired power plants has been proven as a potential approach in the utilization of solar energy to reduce coal consumption. Moreover, solar augmentation offers low cost and low risk alternatives to stand-alone solar thermal power plants. In this study, the annual performance of a solar tower aided coal-fired power (STACP) system is investigated, and the
\end{abstract} influence of thermal storage system capacity on the annual solar generating power and annual solar-toelectricity efficiency is explored. The thermal storage system capacity is optimized to obtain the lowest levelized cost of electricity (LCOE). At the same time, the influence and sensitivity of several important economic factors are explored and assessed. Results demonstrate that compared to a coal-fired power system, the reduction in the annual average coal consumption rate of the STACP system with high direct normal irradiance (DNI), medium DNI, and low DNI are 5.79, 4.52, and $3.22 \mathrm{~g} / \mathrm{kWh}$, respectively. At a minimum, the annual coal consumption can be reduced by $14,000 \mathrm{t}$ in a $600 \mathrm{MW}$ power generation unit. Because the same solar field is considered under different DNI conditions, the LCOE in the high DNI, 
medium DNI, and low DNI scenarios are all fairly similar $(6.37,6.40$, and $6.41 \not / \mathrm{kWh}$, respectively). When the solar multiple is 3.0, the optimal thermal storage capacity of the STACP system, with high, medium, and low DNIs are $6.73,4.42$, and $2.21 \mathrm{~h}$, respectively. The sensitivity analysis shows that the change in economic parameters exerts more influence on the STACP system with the high DNI compared with the other two scenarios.

Keywords: annual performance, solar tower aided coal-fired power plant, solar multiple, thermal energy storage capacity, optimization

\begin{tabular}{|ll|}
\hline \multicolumn{2}{|l|}{ Nomenclature } \\
Abbreviations \\
CSP & Concentrated solar power \\
GA & Genetic algorithm \\
H-DNI & STACP system with high DNI \\
LCOE & Levelized cost of electricity \\
L-DNI & STACP system with low DNI \\
M-DNI & STACP system with medium DNI \\
PSO & Particle swarm optimization \\
PSO-GA & Hybrid optimization algorithm that combines PSO and GA \\
SACP & Solar aided coal-fired power system \\
SM & Solar multiple \\
STACP & Solar tower aided coal-fired power system \\
TES & Thermal energy storage \\
& \\
Mathematical Symbols \\
A & area, $\mathrm{m}^{2}$ \\
$\mathrm{a}_{\mathrm{xt}}$ & system emissivity \\
$\mathrm{B}_{\mathrm{j}}$ & calculation coal consumption rate, $\mathrm{kg} / \mathrm{s}$ \\
$\mathrm{b}_{\mathrm{s}}$ & standard coal consumption rate, $\mathrm{kg} / \mathrm{kWh}$ \\
C & cost, US $\$$ \\
CC & total capital cost, US $\$$ \\
SCC & standard coal consumption, $\mathrm{t}$ \\
$\mathrm{c}_{\mathrm{p}}$ & specific heat of molten salt at constant pressure, $\mathrm{J} /(\mathrm{kg} \mathrm{K)}$ \\
CRF & capital recovery factor \\
$\mathrm{c}_{1}$ and $\mathrm{c}_{2}$ & learning coefficients \\
D & lifetime of STACP system, year \\
DC & direct cost, US $\$$ \\
&
\end{tabular}




\begin{tabular}{|c|c|}
\hline DNI & direct normal irradiance, $\mathrm{W} / \mathrm{m}^{2}$ \\
\hline $\mathrm{E}$ & $\mathrm{CO}_{2}$ emission rate, $\mathrm{g} / \mathrm{kWh}$ \\
\hline Em & $\mathrm{CO}_{2}$ emission, $\mathrm{t}$ \\
\hline$f_{\text {mix }, \mathrm{i}}$ & mixed convection coefficient \\
\hline $\mathrm{h}$ & specific enthalpy, $\mathrm{kJ} / \mathrm{kg}$ \\
\hline $\mathrm{K}$ & heat transfer coefficient \\
\hline LHV & low heating value, $\mathrm{kJ} / \mathrm{kg}$ \\
\hline $\mathrm{m}$ & mass, $\mathrm{kg}$ \\
\hline$\dot{\mathrm{m}}$ & mass flow rate, $\mathrm{kg} / \mathrm{s}$ \\
\hline $\mathrm{n}_{1}$ and $\mathrm{n}_{2}$ & two random numbers \\
\hline O\&M & annual operating and maintenance expenditure, US\$ \\
\hline $\mathrm{P}$ & power, GWh \\
\hline $\mathrm{p}$ & pressure, $\mathrm{MPa}$ \\
\hline$P_{c}$ & crossover probability \\
\hline $\mathrm{P}_{\mathrm{m}}$ & mutation probability \\
\hline Q & thermal energy, $\mathrm{kWh}$ or $\mathrm{kJ} / \mathrm{kg}$-coal \\
\hline q & thermal power, $\mathrm{kW}$ \\
\hline $\mathrm{r}$ & discount rate, $\%$ \\
\hline $\mathrm{T}$ & temperature, $\mathrm{K}$ \\
\hline $\mathrm{U}$ & overall heat transfer coefficient, $\mathrm{kW} /\left(\mathrm{m}^{2} \cdot \mathrm{K}\right)$ \\
\hline $\mathrm{VC}$ & mean net heat capacity rate of the combustion products per unit, $\mathrm{kJ} /(\mathrm{kg} \cdot \mathrm{K})$ \\
\hline $\mathrm{V}$ & volume, $\mathrm{m}^{3} / \mathrm{kg}$-coal \\
\hline $\mathrm{W}$ & coefficient of inertia \\
\hline \multicolumn{2}{|c|}{ Greek Symbols } \\
\hline$\alpha$ & solar evaluation angle \\
\hline$\beta$ & specific enthalpy drop of extraction steam, $\mathrm{kJ} / \mathrm{kg}$ \\
\hline$\gamma$ & specific enthalpy drop of drain water, $\mathrm{kJ} / \mathrm{kg}$ \\
\hline$\Delta \alpha$ & air leakage ratio \\
\hline$\Delta \mathrm{t}$ & time interval, $\mathrm{s}$ \\
\hline$\delta$ & concerning solar absorptance \\
\hline$\varepsilon$ & total hemispherical emittance \\
\hline$\eta_{\mathrm{b}}$ & boiler thermal efficiency \\
\hline$\eta_{\text {hel }}$ & heliostat efficiency \\
\hline$\eta_{\text {sol }}$ & annual solar-to-electricity efficiency \\
\hline$\lambda$ & thermal conductivity of molten salt, $\mathrm{W} /(\mathrm{m} \cdot \mathrm{K})$ \\
\hline$\rho$ & density, $\mathrm{kg} / \mathrm{m}^{3}$ \\
\hline$\sigma_{0}$ & Stefan-Boltzmann constant, $5.67 \times 10^{-8} \mathrm{~W} /\left(\mathrm{m}^{2} \mathrm{~K}^{4}\right)$ \\
\hline$\tau$ & specific enthalpy change of feed-water, $\mathrm{kJ} / \mathrm{kg}$ \\
\hline$\varphi$ & heat retention factor \\
\hline \multicolumn{2}{|c|}{ Subscripts } \\
\hline 0 & original power unit \\
\hline ad & adiabatic \\
\hline
\end{tabular}




\begin{tabular}{|ll|} 
amb & ambient \\
an & annual \\
b & average \\
con & boiler \\
d & convection \\
de & drain water \\
fal & design point \\
fl & falling \\
flue & flame \\
fur & flue gas \\
fw & furnace \\
h & feed-water \\
hel & heating surface \\
ht & heliostat \\
i & hot tank \\
in & ith $_{\text {extraction or ith heater }}$ \\
ini & inlet \\
j & initial \\
max & jth hour in the year \\
ms & maximum \\
out & molten salt \\
rad & outlet \\
rec & radiation \\
ref & receiver \\
sf & reflection \\
rh & solar field \\
sh & reheat steam \\
sol & superheat steam \\
sol-b & solar \\
st & solar energy absorbed by the boiler \\
wf & standard coal \\
\hline & working fluid \\
\hline
\end{tabular}

\section{Introduction}

In the past century, the extensive use of fossil fuels has led to an increase in the carbon dioxide level in the earth's atmosphere, resulting in global warming and climate change [1-3]. One approach to contend with this trend is by increasing power generation through renewables, which is an ongoing topic of research and development. The concentrated solar power (CSP) is a promising renewable technology 
that can displace fossil fuels and could perform an important function in the future power mix. However, the large-scale integration of solar energy into the electric grid presents major technical problems, because, as an intermittent energy source, solar energy requires either energy storage or fuel-based backup power so that it can provide power to satisfy the electric grid's demand [4].Compared with a coal-fired power plant, the CSP plant requires a larger initial investment and a thermal energy storage (TES) system $[1,5,6]$. Therefore, considering the desirability of reducing coal use, the drawback of operating a CSP alone and the potential for both plants to use the same Rankine cycle, it seems sensible to explore the potential benefit of integrating solar thermal energy into coal-fired power plants. In coalfired power plants that are augmented with solar energy, the sharing of the same power block components would be cheaper than operating separate coal and solar plants. This process is known as a solar aided coal-fired power (SACP) system, which was first proposed and studied by Zoschak and Wu in 1975 [7].

Since the 1970s, researchers have begun to study the SACP system. Different integration configurations of the SACP system were proposed by Hu et al. [8] and Yang et al. [9] to preheat feedwater by solar energy. Odeh et al. analyzed three configurations in which the solar heat is used for boiling, preheating, and both boiling and preheating; this study demonstrated that boiling offers the best configuration [10]. Rech et al. explored 22 different design options of the SACP system (in combination with parabolic trough collectors, linear Fresnel collectors or solar towers); the results showed that the highest hybrid thermal efficiency (42.67\%) is obtained using parabolic trough collectors to generate additional high-pressure steam from the drainage water of the last two parallel preheaters [11]. Recently, Wu et al. proposed a new integration scheme that includes two solar fields. One is arranged in parallel with the high-pressure feed-water heaters, and the other is arranged in series between the high-pressure cylinder and re-heaters in the boiler [12]. The results showed that by adding the second solar field, the 
efficiency of the SACP system improved by $1.91 \%$. In terms of the SACP system performances, the study of Zhao et al. demonstrated that the addition of solar heat of approximately $300 \square$, could achieve a relatively higher solar-electricity efficiency. The efficiency results from the use of a higher energy level of the replaced steam extractions, higher collector efficiency, and higher turbine internal efficiency [13]; similar results were also reported by Reddy et al. [14] and Popov [15]. Pierce et. al. compared the SACP system with a stand-alone solar thermal power system and found that the annual solar generating electricity from the SACP system is $25 \%$ greater than that of the stand-alone solar thermal system [16]. Bakos et al. simulated a $300 \mathrm{MW}_{\mathrm{e}} \mathrm{SACP}$ plant with a solar field modification to increase the efficiency from 33 to $37.6 \%$ [17]. Hou et al. investigated the SACP system under different operational modes (power-boosting and fuel-saving) and part load conditions [18]. Huang et al. analyzed the influences of power station capacities and sizes of solar fields [19]. Li et al. [2] and Hong et al. [20] investigated the solar-electricity efficiency of the hybrid system with different temperatures of the collected solar heat. Peng et al. explored the off-design performances of a $330 \mathrm{MW}_{\mathrm{e}} \mathrm{SACP}$ system [21]. Li et al. [6] and Hou et al. [22] explored the boiler's performance after solar energy is introduced to the coal-fired power system. Wu at al. studied the annual performance considering different TES capacities, solar field size, and tracking mode $[23,24]$. Zhang et al. simulated a 330 MW SACP unit with different solar energy inputs from 0 to $2.13 \times 10^{8} \mathrm{~kJ} / \mathrm{h}$; the coal saving rate and the solar power generation share increased to $6.4 \%$ and $7.74 \%$, respectively [25]. Qin et al. performed the analysis of the SACP system under different operating methods and configurations [26-28]. These foregoing studies indicate that the SACP system is a promising and viable option for the present and future power generation because of its dispatchability and lower solar energy cost. To further improve the performances of the SACP system, some studies have examined the optimization of this hybrid system. Zhai et al. optimized the solar collector area 
through a genetic algorithm for these hybrid systems [29, 30]. Zhao et al. presented an economic optimization of the solar multiple in the SACP system considering different unit capacities. For the specific cases in their study, the optimum solar multiple and the relevant lowest levelized cost of electricity (LCOE) are 1.4 US\$/kWh and $0.089 \mathrm{US} \$ / \mathrm{kWh}$, respectively for a $200 \mathrm{MW}_{\mathrm{e}}$ unit; 1.3 US\$ $\$ \mathrm{kWh}$ and $0.084 \mathrm{US} \$ / \mathrm{kWh}$, respectively, for a $330 \mathrm{MW}_{\mathrm{e}}$ unit; $1.3 \mathrm{US} \$ / \mathrm{kWh}$ and $0.078 \mathrm{US} \$ / \mathrm{kWh}$, respectively, for a $600 \mathrm{MW}_{\mathrm{e}}$ unit (the exchange rate from US\$ to RMB is set as 6.3). [31]. In a similar study, Wang et al. conducted a technical and economical optimization of the SACP system; the results showed efficiencies within the range of $13-20 \%$, depending on the solar multiple and substituting method used [32]. Zhong et al. optimized the integration mode for the SACP system and applied a mixed-integer nonlinear programming approach to optimize the oil-water heat exchanger area based on the annual direct normal irradiance (DNI) distribution. The optimized results of a $150 \mathrm{MW}_{\mathrm{e}} \mathrm{SACP}$ system indicate that a solar aided system that can be flexibly switched among different feed-water heaters according to the DNI, and that this would result to a lower LCOE than a solar aided system that is fixed to one specific heater [33]. Some researchers have focused their efforts on the evaluation methods. Zhai et al. proposed the solar contribution evaluation method for a $660 \mathrm{MW}_{\mathrm{e}} \mathrm{SACP}$ system to explore the system performance under five different loads $(100,85,75,50$, and $40 \%)[34,35]$. Subsequently, the same group developed a thermos-economic structural theory for both the power-boosting and fuel-saving modes [36]. Wang et al. evaluated the different modes of solar aided coal-fired power generation system through theoretical calculations [37]. Zhu et al. studied solar aided coal-fired power plants with five solar contribution methods in a comparative approach and indicated the future scenarios and associated subsidies for energy production [38]. Zhao et al. [39] evaluated the solar hybrid system according to energy level, and results demonstrated the SACP system shows a better performance at temperatures below $330 \square$; whereas with 
the solar heat that is above $330 \square$, the integrated solar combined cycle system with the solar heat generating high-pressure saturated steam has the best thermodynamic performance. Moreover, the theoretical solar-electricity efficiency reaches a peak value when the solar heat used for the SACP system between 300 and $400 \square$. Suresh et al. [40] and Adibhatla et al. [41] applied the 4-E (Energy, Exergy, Environment, and Economic) method to the SACP system. Peng et al. evaluated the SACP system by using an energy-utilization diagram. Results showed that the exergy destruction of the SACP plant is lower than that of the solar-only thermal power plant; moreover, the LCOE of the SACP plant is approximately $20-30 \%$ lower than that of the solar-only thermal power plant [42]. Hou et al. proposed a new evaluation method of the solar contribution in the SACP system based on an exergy analysis. A solar aided $600 \mathrm{MW}_{\mathrm{e}}$ coal-fired unit was studied, and the results showed that a solar contribution of $25.7 \mathrm{MW}_{\mathrm{e}}$ and a solar-to-electricity efficiency of $24.1 \%$ was possible in the fuel-saving mode [43].

However, these studies only investigated the SACP system by assuming that the solar thermal input is from a parabolic collector that achieves temperatures within the range 300-400 $\square$; therefore, the integration into the SACP system aims to preheat feed-water to reduce extracted steam from the turbine. The study of Zoschak and Wu showed that combining solar energy with the evaporator and super-heaters yields a better performance than using solar energy to preheat feed-water [7]. Integrating solar energy with evaporation and superheating in the boiler would require a higher operational temperature of the solar field because the temperature of superheat steam is normally over $500 \square$, which is considerably higher than the feed-water temperature $(<300 \square)$. A solar tower aided coal-fired power (STACP) system, can operate at such high temperatures with a relatively higher efficiency. Zhang et al. proposed two schemes for introducing the solar tower to the boiler of a $660 \mathrm{MW}_{\mathrm{e}}$ coal-fired power plant. Results showed that the standard coal consumption rate could be reduced by over $17 \mathrm{~g} / \mathrm{kWh}$ [44]. In their 
subsequent work, the annual performance of the two schemes with thermal energy storage, which uses a one-tank thermocline technology, was investigated. Results showed that the annual solar power efficiency was approximately $16-20 \%[5]$.

Based on the detailed literature review above, it can be observed that numerous studies have been performed on the solar-coal hybrid system using the solar parabolic trough technology. However, a considerably limited amount of work has been reported regarding the solar tower concept that is integrated with the evaporation and superheating section of the boiler. Additionally, the thermal storage capacity optimization, which can enhance economic performance on different solar multiples in the STACP system has not been reported in open literature. Interestingly, these studies (regarding solar tower technology) calculated the hybrid system performance with the assumption that the constant power output and real-time power load of the unit are not considered. Based on our previous study [45], the quantity of solar energy that can be used by the boiler is decided by the TES system and its unit power load. Therefore, the TES system and its unit power load have a significant influence on the annual performance of the STACP system. To satisfy the innovation requirements, the annual performance of the most efficient STACP system proposed in our earlier study [46] is further investigated. The main contributions of this study are as follows, (1) The boiler model is developed in detail instead of treating it as a "black box". The improved boiler model can determine the maximum solar energy consumed by the hybrid system at different power loads, whereas the "black box" model inevitably compromises accuracy. (2) For the first time, the annual thermal, environmental, and economic performances of a 600 $\mathrm{MW}_{\mathrm{e}}$ STACP system are investigated with the consideration of the real time power load. (3) Three different DNI values are considered to demonstrate the influence of the DNI on the annual performances. (4) The influence of the TES capacity on the annual solar generating power and annual solar-to-electricity 
efficiency are investigated. (5) The PSO-GA method is employed to optimize the TES capacity of different solar multiples to obtain the lowest LCOE. (6) Sensitivity analysis is implemented to explore the influence of several important economic factors with the consideration of the different DNI values and solar multiples.

\section{System description}

2.1 Solar tower aided coal-fired power system

The STACP system consists of the original coal-fired power system and the added solar field, as shown in Fig. 1. The solar field is composed of a radial staggered heliostat field, solar tower, a molten salt receiver, two-tank molten salt thermal storage system, and steam generator (SG). The solar energy is reflected to the receiver by the heliostats. The cold molten salt is pumped through the receiver to be heated and stored in the hot tank. According to the operational strategy of the STACP system, the flow rate of the molten salt out of the hot tank to the heat exchangers in the power plant can be adjusted and is independent of the flow rate through the receiver. After releasing the thermal energy to the steam/water in the steam generator, the molten salt flows into the cold tank. The original coal-fired power system is based on a regenerative Rankine cycle. The system consists of a boiler, turbine, generator, feed-water heaters, deaerator, condenser and pumps. Coal is the primary energy source in the original coal-fired power system. In the boiler, the thermal energy is released by coal combustion, which heats the steam to the designed pressure and temperature. Thereafter, the steam is expanded in the turbine to generate power before being condensed back to feed-water in the condenser. Next, the feed-water from the condenser enters the boiler after going through the condensate pump, four low-pressure heaters ( $\mathrm{H} 5, \mathrm{H} 6, \mathrm{H} 7$, and $\mathrm{H} 8$ ), one deaerator (H4), one feed-water pump, and three high-pressure heaters (H1, H2, and $\mathrm{H} 3$ ), which are all used to increase the average temperature of the regenerative Rankine cycle. 
A part in the purple box in Fig. 1 shows the schematic structure of a boiler. Coal burns in the furnace and releases its radiative energy, which is absorbed by the water wall and other heat exchangers such as the first platen super-heater (FPS), the second platen super-heater (SPS), and the high-temperature reheater (HR). Thereafter, the flue gas flows through the FPS, SPS, HR, final super-heater (FS), lowtemperature re-heater (LR), economizer (ECO), and air preheater (APH). The gas is cooled down by the superheat steam, reheat steam, feed-water and air. In the STACP system, feed-water first goes to the ECO and the feed-water outlet from the ECO is divided into two parts. One part flows into the SG to absorb solar energy from the molten salt pumped from the TES system. This water is heated to the same condition as superheat steam. The other part flows through the furnace to the steam separator (SEP) in the boiler. Then, the separated steam, also known as superheat steam, passes through the FPS, SPS, and FS. Afterwards, the superheat steam mixes with the steam from the solar steam generator and enters the high-temperature turbine (HP) to produce power. Later, the steam from the HP returns to the boiler for reheating to improve the work capacity and efficiency by increasing the average heat addition temperature. Then, the reheat steam is transported to the intermediate-pressure turbine (IP) and the lowpressure turbine (LP) to produce further electric power. 


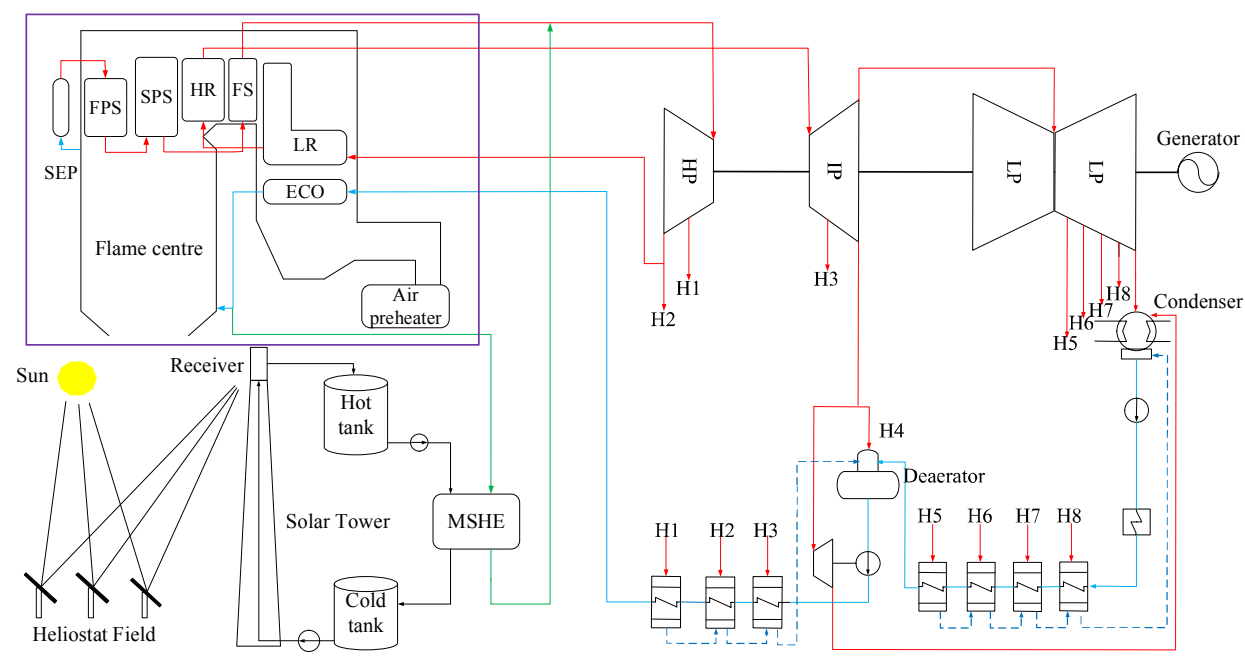

Fig.1 Solar aided coal-fired power system diagram

\subsection{Operational strategy of STACP system}

The logic flow chart of the STACP performance simulation model is shown in Fig, 2. When the solar altitude angle is larger than $15^{\circ}$ and the DNI is higher than $150 \mathrm{~W} / \mathrm{m}^{2}$, the heliostats are focused onto the receiver. Then, the DNI, heliostat field efficiency, receiver efficiency integrated over the time of operation define the solar energy collected by the receiver $\left(\mathrm{Q}_{\mathrm{rec}}\right)$ and the thermal energy flowing into the hot tank; the stored energy in the tank $\left(\mathrm{Q}_{\mathrm{ht}}\right)$ can be calculated. If $\mathrm{Q}_{\mathrm{rec}}$ is greater than $\mathrm{Q}_{\mathrm{ht}, \max }-\mathrm{Q}_{\mathrm{ht}}\left(\mathrm{Q}_{\mathrm{ht} \text {,max }}\right.$ : TES capacity), then, the superfluous thermal energy will be discarded by defocusing some of the heliostats. Based on the annual power load of the unit and our previous study [45], the maximum solar power that can be absorbed by the boiler $\left(\mathrm{q}_{\text {boiler,max }}\right)$ and the solar power introduced into the boiler $\left(\mathrm{q}_{\text {sol-b }}\right)$ can be calculated. Finally, the boiler performance after the solar power is introduced, and the solar generated power is calculated. When the DNI is insufficient but $\mathrm{Q}_{\mathrm{ht}}$ is not zero, the system can operate in a hybrid mode by using the energy stored in the TES system. 


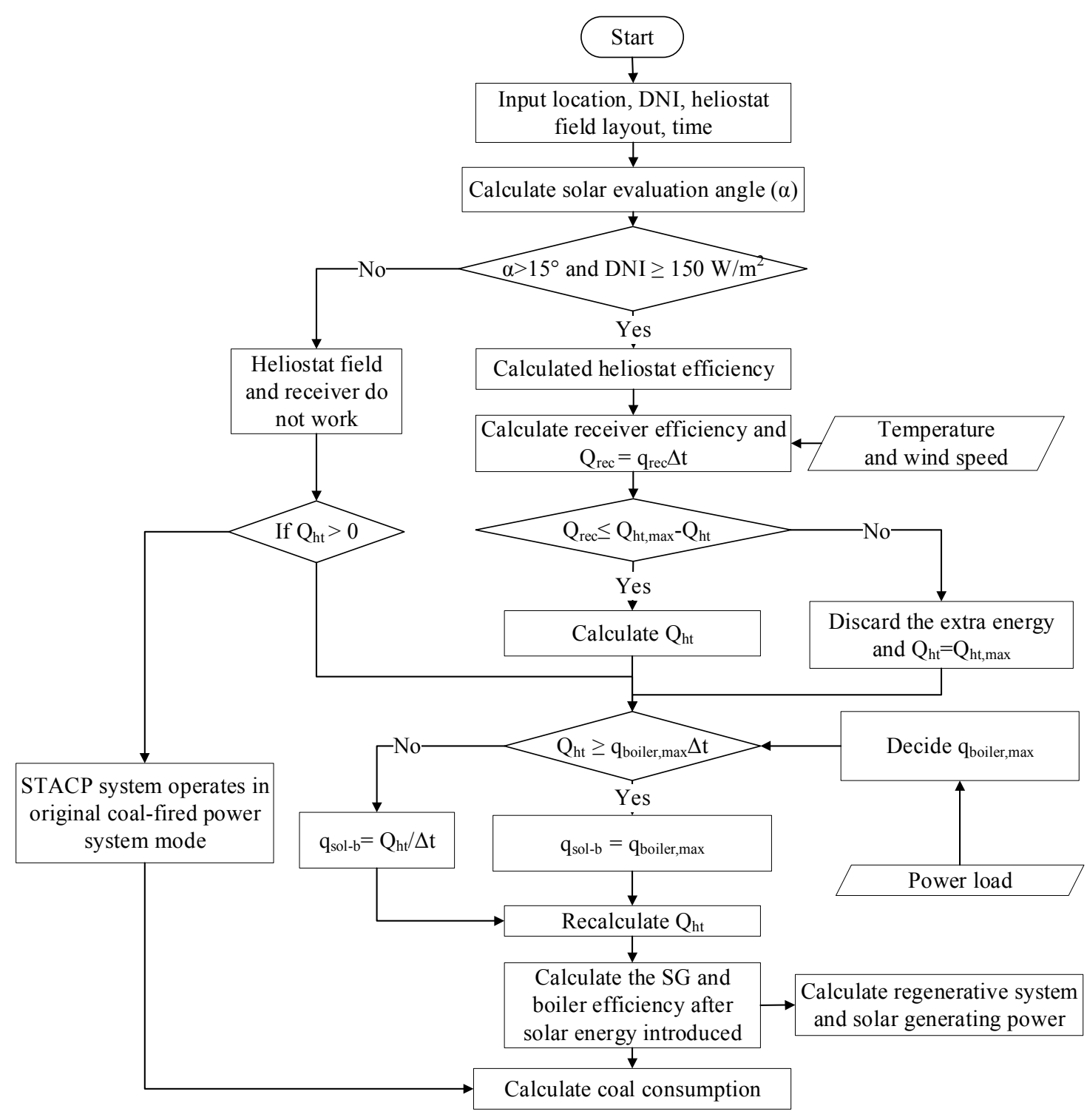

Fig. 2 Logic flow chart of the STACP performance simulation model

\section{Modeling Methodology}

\subsection{Heliostat field}

The heliostat field consists of many individual heliostats, which surround the solar tower and reflect

solar energy to the receiver. The thermal power reflected to the receiver can be calculated as follows:

$$
\mathrm{q}_{\text {hel }}=\mathrm{q}_{\mathrm{fal}} \cdot \eta_{\text {hel }}
$$

where $q_{\text {hel }}$ is the solar power reflected by the heliostats; $\eta_{\text {hel }}$ is the heliostat efficiency, which is 
composed of the mirror reflectivity, cosine factor, atmospheric attenuation factor, shading and blocking factor and interception factor. The calculation method of the heliostat efficiency is shown in Appendix A $[47,48]$. The PSO-GA method (section 3.8) is used to optimize the layout of the heliostat field to reach the maximum annual heliostat field efficiency by adjusting azimuthal and radial distances between two contiguous heliostats; $\mathrm{q}_{\mathrm{fal}}$ is the maximum solar power falling on the total heliostat area and can be calculated as follows:

$$
\mathrm{q}_{\mathrm{fal}}=\mathrm{A}_{\mathrm{hel}} \cdot \mathrm{DNI} / 10^{3}
$$

where $A_{\text {hel }}$ is the total area of all heliostat mirrors.

3.2 Receiver

The receiver at the top of the tower is used to transfer the power collected by the heliostat field to the molten salt. The power balance for the receiver is as follows:

$$
\begin{gathered}
\mathrm{q}_{\text {rec }}=\mathrm{q}_{\text {hel }}-\mathrm{q}_{\text {rec,loss }} \\
\mathrm{q}_{\text {rec,loss }}=\mathrm{q}_{\text {ref }}+\mathrm{q}_{\text {rad }}+\mathrm{q}_{\text {con }}
\end{gathered}
$$

where $q_{r e c}$ is the power absorbed by the molten salt in the receiver; $q_{r e c, l o s s}$ is the power loss in the receiver; $q_{\text {ref }}$ is the power loss reflected from the tube surface; $q_{r a d}$ is the radiation loss of receiver; $\mathrm{q}_{\text {con }}$ is the convection loss of receiver. The foregoing $\left(\mathrm{q}_{\mathrm{ref}}, \mathrm{q}_{\text {rad }}\right.$ and $\left.\mathrm{q}_{\text {con }}\right)$ can be calculated by the following[49]:

$$
\begin{gathered}
\mathrm{q}_{\text {ref }}=(1-\delta) \mathrm{q}_{\text {hel }} \\
\mathrm{q}_{\text {rad }}=\sum \varepsilon \sigma_{0} \mathrm{~A}\left(\mathrm{~T}_{\text {wall,i }}^{4}-\mathrm{T}_{\text {amb }}^{4}\right) \\
\mathrm{q}_{\text {con }}=\sum \mathrm{f}_{\text {mix,i }} \mathrm{A}\left(\mathrm{T}_{\text {wall,i }}-\mathrm{T}_{\text {amb }}\right)
\end{gathered}
$$

where $\delta$ is concerning solar absorptance of the tube panels, which is $0.95 ; \varepsilon$ is the hemispherical emittance, which is $0.88 ; \sigma_{0}$ is the Stefan-Boltzmann constant; A is the lateral surface of the tube; 
$f_{\text {mix, } i}$ is the mixed convection coefficient; $T_{\text {wall, } i}$ is the wall temperature; $T_{a m b}$ is the ambient air temperature.

\subsection{Thermal energy storage system}

The TES system is a typical two-tank molten salt type composed of hot and cold tanks and associated molten salt pumps. At the beginning of a day, the molten salt is stored in the cold tank. When the heliostat field starts to work, the receiver is sufficiently warmed, and molten salt is pumped to the receiver to absorb thermal energy. After heating, the salt is conveyed to the hot tank and is ready to be used to generate steam in the steam generator. The mass and energy balance for the two-tank molten salt storage tanks are similar. For example, in the hot tank,

$$
\begin{gathered}
\mathrm{m}_{\mathrm{ht}}=\mathrm{m}_{\text {ini }}+\left(\dot{\mathrm{m}}_{\mathrm{ms}, \mathrm{in}}-\dot{\mathrm{m}}_{\mathrm{ms}, \text { out }}\right) \Delta \mathrm{t} \\
\mathrm{Q}_{\mathrm{ht}}=\mathrm{Q}_{\mathrm{ini}}+\left(\mathrm{q}_{\mathrm{in}}-\mathrm{q}_{\mathrm{out}}-\mathrm{q}_{\mathrm{ht}, \text { loss }}\right) \Delta \mathrm{t} / 3600 \\
q_{\mathrm{ht}, \text { loss }}=\mathrm{UA}\left(\mathrm{T}_{\mathrm{ht}}-\mathrm{T}_{\mathrm{amb}}\right)
\end{gathered}
$$

where $\mathrm{m}_{\mathrm{ht}}$ is the mass of molten salt in the hot tank; $\mathrm{m}_{\mathrm{ini}}$ is the initial mass of molten salt in the hot tank; $\dot{\mathrm{m}}_{\text {in }}$ and $\dot{\mathrm{m}}_{\text {out }}$ are the mass flow rates of molten salt in and out of the hot tank, respectively; $\Delta \mathrm{t}$ is the time interval; $\mathrm{Q}_{\mathrm{ht}}$ is the energy stored in the hot tank; $\mathrm{Q}_{\mathrm{ini}}$ is the initial energy stored in the hot tank; $\mathrm{q}_{\text {in }}$ and $\mathrm{q}_{\text {out }}$ are the thermal power in and out of the hot tank, respectively; $\mathrm{q}_{\mathrm{ht} \text {,loss }}$ is the thermal power loss, and $\mathrm{U}$ is the overall heat transfer coefficient, which is set to the value recommended in the System Advisor Model (SAM) software; $A$ is the heat transfer area; $T_{h t}$ is the temperature of the hot tank; $\mathrm{T}_{\text {amb }}$ is the ambient temperature

\subsection{Steam generator}

The steam generator is simplified to a "molten salt-to-water/steam" heat exchanger in this study, which contains both evaporation and superheating sections of the supercritical water/steam. The power 
balance of the heat exchanger can be expressed as follows:

$$
\begin{gathered}
\mathrm{q}_{\text {solar }}=\dot{\mathrm{m}}_{\mathrm{ms}}\left(\mathrm{h}_{\mathrm{ms}, \text { in }}-\mathrm{h}_{\mathrm{ms}, \text { out }}\right) \\
\mathrm{q}_{\mathrm{wf}}=\dot{\mathrm{m}}_{\mathrm{wf}}\left(\mathrm{h}_{\mathrm{wf}, \text { out }}-\mathrm{h}_{\mathrm{wf}, \text { in }}\right)
\end{gathered}
$$

where, $\mathrm{q}_{\text {solar }}$ and $\mathrm{q}_{\mathrm{wf}}$ are both the power transferred to the water/steam; $\dot{\mathrm{m}}_{\mathrm{ms}}$ is the mass flow rate of molten salt; $h_{m s, i n}$ and $h_{m s, o u t}$ are the specific enthalpies of molten salt in and out of the SG, respectively; $\dot{\mathrm{m}}_{\mathrm{wf}}$ is the mass flow rate of working fluid (water/steam); $\mathrm{h}_{\mathrm{wf}, \text { in }}$ and $\mathrm{h}_{\mathrm{wf}, \text { out }}$ are the specific enthalpies of working fluid in and out of SG, respectively.

\subsection{Boiler}

\subsubsection{Heat balance for the boiler}

The boiler model is established based on the research undertaken in the former Soviet Union in 1973 and modified in China in 1998 [50]. The heat balance of the boiler can be calculated by the follows:

$$
\mathrm{q}_{\mathrm{b}}=\dot{\mathrm{m}}_{\mathrm{sh}}\left(\mathrm{h}_{\mathrm{sh}}-\mathrm{h}_{\mathrm{fw}}\right)+\dot{\mathrm{m}}_{\mathrm{rh}}\left(\mathrm{h}_{\mathrm{rh}, \mathrm{out}}-\mathrm{h}_{\mathrm{rh}, \mathrm{in}}\right)-\mathrm{q}_{\mathrm{wf}}=\dot{\mathrm{m}}_{\mathrm{coal}} \cdot \mathrm{LHV}_{\mathrm{b}}
$$

where $\mathrm{q}_{\mathrm{b}}$ is the heat absorbed by the water/steam in the boiler; $\dot{\mathrm{m}}_{\mathrm{sh}}$ and $\dot{\mathrm{m}}_{\mathrm{rh}}$ are the mass flow rates of the main steam and reheat steam, respectively; $h_{f w}$ is the specific enthalpy of feed-water; $h_{s h}$ is the specific enthalpy of superheat steam; $h_{r h, i n}$ and $h_{r h, o u t}$ are the specific enthalpies of reheat steam in and out of boiler, respectively; $\dot{\mathrm{m}}_{\text {coal }}$ is the mass flow rate of coal; LHV is the low heating value of the coal used in this study; $\eta_{b}$ is the boiler efficiency.

\subsubsection{Heat balance in furnace}

In the furnace, radiative heat transfer is predominant, and convection heat transfer can be neglected [50]. According to the principle of energy conservation, the heat absorption from the flue gas in the furnace can be considered equal to the enthalpy drop from the adiabatic flame temperature to that at the outlet of the furnace. Therefore, the basic equation for furnace heat transfer calculation is as follows: 


$$
\mathrm{q}_{\text {fur }}=\varphi \mathrm{B}_{\mathrm{j}} \mathrm{VC}\left(\mathrm{T}_{\text {ad,fl }}-\mathrm{T}_{\text {fur,out }}\right)=10^{-3} \mathrm{a}_{\mathrm{xt}} \mathrm{A}_{\text {fur }} \sigma_{0}\left(\mathrm{~T}_{\text {ave,fl }}^{4}-\mathrm{T}_{\text {ave,fur }}^{4}\right)
$$

where $q_{f u r}$ is the heat absorbed in the furnace; $\varphi$ is the heat retention factor; $B_{j}$ is the calculated coal consumption rate; $\mathrm{VC}$ is the mean net heat capacity rate of the combustion products per unit; $\mathrm{T}_{\mathrm{ad}, \mathrm{fl}}$ is the adiabatic flame temperature; $T_{\text {fur,out }}$ is the temperature at the outlet of the furnace; $a_{x t}$ is the system emissivity; $\mathrm{A}_{\text {fur }}$ is the furnace enclosure wall area; $\mathrm{T}_{\text {ave,fl }}$ and $\mathrm{T}_{\text {ave,fur }}$ are the average temperatures of the flame and furnace wall, respectively.

\subsubsection{Heat balance in convective heat exchangers}

The convective heating surfaces refer to all the heating surfaces in the flue gas that pass beyond the furnace outlet. The heat balance equations for the convective heating surface are as follows:

$$
\mathrm{Q}_{\text {con }}=\frac{K \mathrm{KA}_{\mathrm{h}} \Delta \mathrm{T}_{\mathrm{LMTD}}}{\mathrm{B}_{\mathrm{j}}}
$$

For the gas side:

$$
\mathrm{Q}_{\text {con }}=\varphi\left(\mathrm{h}_{\text {flue, in }}-\mathrm{h}_{\text {flue, out }}+\Delta \alpha \mathrm{h}_{\text {air }}\right)
$$

For the working fluid side:

$$
\mathrm{Q}_{\mathrm{con}}=\frac{\dot{\mathrm{m}}_{\mathrm{wf}}\left(\mathrm{h}_{\mathrm{wf}, \text { out }}-\mathrm{h}_{\mathrm{wf}, \mathrm{in}}\right)}{\mathrm{B}_{\mathrm{j}}}-\mathrm{Q}_{\mathrm{rad}}
$$

where $Q_{\text {con }}$ is the convective heat transferred; $K$ is the heat transfer coefficient; $A_{h}$ is the heating surface area; $\Delta \mathrm{T}_{\mathrm{LMTD}}$ is the logarithmic mean temperature difference; $\mathrm{h}_{\text {flue, in }}$ and $\mathrm{h}_{\text {flue,out }}$ are the specific enthalpies of flue gas in and out of the heater, respectively; $\Delta \alpha$ is the air leakage ratio; $h_{\text {air }}$ is the specific enthalpy of cold air; $\mathrm{m}_{\mathrm{wf}}$ is the mass flow rate of steam/water; $\mathrm{h}_{\mathrm{wf}, \text { in }}$ and $\mathrm{h}_{\mathrm{wf}, \text { out }}$ are the specific enthalpies of steam in and out of the heater, respectively; $\mathrm{Q}_{\mathrm{rad}}$ is radiative heat transferred.

\subsection{Turbine and regenerative system}

In this study, the energy balance matrix used to calculate the turbine and regenerative system can be expressed as follows: 


$$
\left[\begin{array}{llllllll}
\beta_{1} & & & & & & & \\
\gamma_{2} & \beta_{2} & & & & & & \\
\gamma_{3} & \gamma_{3} & \beta_{3} & & & & & \\
\gamma_{4} & \gamma_{4} & \gamma_{4} & \beta_{4} & & & & \\
\tau_{5} & \tau_{5} & \tau_{5} & \tau_{5} & \beta_{5} & & & \\
\tau_{6} & \tau_{6} & \tau_{6} & \tau_{6} & \gamma_{6} & \beta_{6} & & \\
\tau_{7} & \tau_{7} & \tau_{7} & \tau_{7} & \gamma_{7} & \gamma_{7} & \beta_{7} & \\
\tau_{8} & \tau_{8} & \tau_{8} & \tau_{8} & \gamma_{8} & \gamma_{8} & \gamma_{8} & \beta_{8}
\end{array}\right]\left[\begin{array}{c}
\dot{\mathrm{m}}_{1} \\
\dot{\mathrm{m}}_{2} \\
\dot{\mathrm{m}}_{3} \\
\dot{\mathrm{m}}_{4} \\
\dot{\mathrm{m}}_{5} \\
\dot{\mathrm{m}}_{6} \\
\dot{\mathrm{m}}_{7} \\
\dot{\mathrm{m}}_{8}
\end{array}\right]=\dot{\mathrm{m}}_{\mathrm{fw}}\left[\begin{array}{c}
\tau_{1} \\
\tau_{2} \\
\tau_{3} \\
\tau_{4} \\
\tau_{5} \\
\tau_{6} \\
\tau_{7} \\
\tau_{8}
\end{array}\right]
$$

where $\dot{\mathrm{m}}_{\mathrm{fw}}$ is the mass flow rate of feedwater from the deaerator; $\dot{\mathrm{m}}_{\mathrm{i}}$ is the mass flow rate of the extraction steam in the $i_{\text {th }}$ stage; $\tau_{\mathrm{i}}$ is the specific enthalpy change of feed-water in the $i_{\text {th }}$ heater; $\beta_{\mathrm{i}}$ is the specific enthalpy drop of the extraction steam in $i_{\text {th }}$ heater; $\gamma_{i}$ is the specific enthalpy drop of drain water in the $\mathrm{i}_{\text {th }}$ heater.

The foregoing $(\beta, \gamma, \tau)$ can be obtained as follows:

$$
\begin{gathered}
\beta_{\mathrm{i}}=\left\{\begin{array}{c}
\mathrm{h}_{\mathrm{i}}-\mathrm{h}_{\mathrm{d}, \mathrm{i}}(\mathrm{i}=1,2,3,5,6,7,8) \\
\mathrm{h}_{\mathrm{i}}-\mathrm{h}_{\mathrm{fw}, 5}(\mathrm{i}=4)
\end{array}\right. \\
\tau_{\mathrm{i}}=\mathrm{h}_{\mathrm{fw}, \mathrm{i}}-\mathrm{h}_{\mathrm{fw}, \mathrm{i}+1} \\
\gamma_{\mathrm{i}}=\left\{\begin{array}{c}
\mathrm{h}_{\mathrm{d}, \mathrm{i}-1}-\mathrm{h}_{\mathrm{d}, \mathrm{i}}(\mathrm{i}=2,3,6,7,8) \\
\mathrm{h}_{\mathrm{d}, 3}-\mathrm{h}_{\mathrm{fw}, 5}(\mathrm{i}=4)
\end{array}\right.
\end{gathered}
$$

where, $h_{i}$ is the specific enthalpy of extraction steam for the $i_{t h}$ heater; $h_{f w, i}$ is the specific enthalpy of feed-water at outlet for the $i_{t h}$ heater; $h_{d, i}$ is the specific enthalpy of drain water in the $i_{\text {th }}$ heater.

To simplify the calculation, the Stodola formula is employed to calculate the off-design condition, which is given as follows[51]:

$$
\frac{\dot{\mathrm{m}}_{\mathrm{i}}}{\dot{\mathrm{m}}_{\mathrm{i}, 0}}=\sqrt{\frac{\mathrm{p}_{\mathrm{i}}^{2}-\mathrm{p}_{\mathrm{i}+1}^{2}}{\mathrm{p}_{\mathrm{i}, 0}^{2}-\mathrm{p}_{\mathrm{i}+1,0}^{2}}}
$$

where $\dot{\mathrm{m}}_{\mathrm{i}}$ is the steam mass flow rate of the $\mathrm{i}_{\text {th }}$ stage of the turbine under off-design condition; $\dot{\mathrm{m}}_{\mathrm{i}, 0}$ is the steam mass flow rate of the $i_{\text {th }}$ stage of the turbine under original design condition; $p_{i}$ and $p_{i+1}$ are the pressures of the $i_{\text {th }}$ and $(i+1)_{\text {th }}$ stages, respectively, in the turbine after the solar energy is introduced; $\mathrm{p}_{\mathrm{i}, 0}$ and $\mathrm{p}_{\mathrm{i}+1,0}$ are the pressures of the $\mathrm{i}_{\mathrm{th}}$ and $(\mathrm{i}+1)_{\mathrm{th}}$ stages, respectively, of the turbine of the original coal-fired power generation unit. 


\subsection{Evaluation criteria}

The solar multiple is an important parameter for a solar thermal power plant. It is defined as the ratio of the heat absorbed by the molten salt in the receiver to that transferred to the power block under the rated design point condition $\left(\mathrm{q}_{\mathrm{de}}\right)$. It can be obtained by the following:

$$
\mathrm{SM}=\frac{\mathrm{q}_{\mathrm{rec}}}{\mathrm{q}_{\mathrm{de}}}
$$

The annual standard coal consumption $\left(\mathrm{SCC}_{\mathrm{an}}\right)$ can be calculated by the following:

$$
\mathrm{SCC}_{\mathrm{an}}=\sum_{\mathrm{i}=1}^{8760} \frac{3.6 \dot{\mathrm{m}}_{\text {coal } \mathrm{j}} \mathrm{LHV}}{\mathrm{LHV}_{\mathrm{st}}}
$$

where $\dot{\mathrm{m}}_{\text {coal, } \mathrm{j}}$ is the mass flow rate of coal in the $\mathrm{j}_{\mathrm{th}}$ hour of the year; $\mathrm{LHV}_{\mathrm{st}}$ is the low heating value of standard coal, which is $29,271 \mathrm{~kJ} / \mathrm{kg}$.

The annual average standard coal consumption rate $\left(b_{s}\right)$ can be obtained by the following:

$$
\mathrm{b}_{\mathrm{s}}=\frac{\mathrm{SCC}_{\mathrm{an}}}{\mathrm{P}_{\mathrm{an}}}
$$

where $\mathrm{P}_{\mathrm{an}}$ is the power generated over one year.

The annual $\mathrm{CO}_{2}$ emission $\left(\mathrm{Em}_{\mathrm{an}}\right)$ can be calculated by the following:

$$
\mathrm{Em}_{\mathrm{an}}=\sum_{\mathrm{i}=1}^{8760} 3.6 \mathrm{~V}_{\mathrm{CO}_{2}} \rho_{\mathrm{CO}_{2}} \mathrm{~m}_{\text {coal }, \mathrm{j}}
$$

where $\mathrm{V}_{\mathrm{CO}_{2}}$ is the volume of $\mathrm{CO}_{2}$ for the combustion of $1 \mathrm{~kg}$ coal; $\rho_{\mathrm{CO}_{2}}$ is the density of $\mathrm{CO}_{2}$.

The annual average $\mathrm{CO}_{2}$ emission rate $\left(\mathrm{E}_{\mathrm{CO}_{2}}\right)$ can be obtained by the following:

$$
\mathrm{E}_{\mathrm{CO}_{2}}=\frac{\mathrm{Em}_{\mathrm{an}}}{\mathrm{P}_{\mathrm{an}}}
$$

The annual solar generating power $\left(\mathrm{P}_{\text {sol,an }}\right)$ can be calculated by the following:

$$
\mathrm{P}_{\mathrm{sol}, \mathrm{an}}=\sum_{\mathrm{i}=1}^{8760} \mathrm{P}_{\mathrm{sol}, \mathrm{j}}
$$

where $\mathrm{P}_{\text {sol, } \mathrm{i}}$ is solar generating power in the $\mathrm{j}_{\mathrm{th}}$ hour of the year. The calculation method of $\mathrm{P}_{\text {sol, } \mathrm{j}}$ used in this study has been obtained from literature [44].

The annual solar-to-electricity efficiency can be obtained by the following: 


$$
\eta_{\mathrm{sol}}=\frac{\mathrm{P}_{\mathrm{sol}, \mathrm{an}}}{3.6 \sum_{\mathrm{i}=1}^{8700} \mathrm{q}_{\mathrm{fal}, \mathrm{j}}}
$$

where $q_{f a l, j}$ is the solar energy falling on the heliostats in the $j_{\text {th }}$ hour of the year.

The levelized cost of electricity is the cost that, if assigned to every unit of the electrical energy produced (or saved) by the system over the lifetime of the plant, will equal the total lifecycle cost when discounted back to the current year [52]. The LCOE of the STACP system, which is also the optimization objective function in this study, can be calculated by the following:

$$
\mathrm{LCOE}=\frac{\mathrm{CC} \cdot \mathrm{CRF}+\mathrm{O} \& \mathrm{M}+\mathrm{C}_{\text {fuel }}+\mathrm{C}_{\mathrm{CO} 2}}{10^{4} \mathrm{P}_{\mathrm{an}}}
$$

where $\mathrm{CC}$ is the total capital cost of the STACP system; CRF is the capital recovery factor defined in Eq. (28); O\&M is the annual operating and maintenance expenditure; $\mathrm{C}_{\text {fuel }}$ is the annual cost of coal; $\mathrm{C}_{\mathrm{CO} 2}$ is the annual $\mathrm{CO}_{2}$ emission penalty cost.

$$
\mathrm{CRF}=\frac{\mathrm{r}(\mathrm{r}+1)^{\mathrm{D}}}{(\mathrm{r}+1)^{\mathrm{D}}-1}
$$

where $\mathrm{r}$ is the discount rate, and $\mathrm{D}$ is the lifetime of the STACP system.

To compare the solar energy cost of different cases, the LCOE of the solar plant components can be calculated by the following:

$$
\mathrm{LCOE}_{\mathrm{sf}}=\frac{\mathrm{CC}_{\mathrm{sf}} \mathrm{CRF}+\mathrm{O} \& \mathrm{M}_{\mathrm{sf}}}{10^{4} \mathrm{P}_{\mathrm{sol}, \mathrm{an}}}
$$

where $\mathrm{CC}_{\mathrm{sf}}$ is the total capital cost of the solar field and all other solar plant components; O\&M $\mathrm{M}_{\mathrm{sf}}$ is the annual operating and maintenance expenditure of solar field and all other solar plant components.

\subsection{Optimization method}

In this study, the TES capacity is optimized to obtain the lowest LCOE by a hybrid optimization algorithm, PSO-GA, which simultaneously executes the genetic algorithm (GA) and particle swarm optimization (PSO). The GA is an evolutionary algorithm with evolution strategies and evolutionary genetic programming to find the solution of optimization problems. The algorithm starts with a 
population, which is composed of several randomly generated individuals and works through an iterative process. With each iteration, a new population is generated by applying certain operators: selection, crossover, and mutation. Selection is an important part in the GA because of its significant impact on solution convergence [53]. In a selection process, several individuals with higher fitness are selected from the old population. Crossover is the process of taking two parents and producing two children solutions from them. Mutation is an operator for changing one gene value of an individual from its initial state. However, because of the GA's stochastic nature, it is not possible to obtain a solution within a certain level of accuracy, which causes excessive computational burden [54]. Similar to the GA, the PSO is also a population based stochastic optimization method. It is initialized with random solutions and searches for a global optimum in successive generations. However, the PSO has no evolutionary operator. The PSO firstly generates a random population and a random initial velocity for each particle in the search space. Then, the objective function for each particle is calculated and the position of each particles are updated, according to its local best position (pbest) and global best position (gbest). Compared with the GA, the particles in the PSO share information among them. They have the tendency to move randomly at the same time, which speeds up the search process. However, the PSO may prematurely converge when processing problems with a small population. The key genetic operators in the GA (namely selection, crossover and mutation) may compensate for this deficiency. Therefore, the combination of the GA and PSO can produce a hybrid algorithm with a better efficiency to achieve optimality.

Similar to the GA and PSO, the hybrid PSO-GA method is also a population-based optimization method in which the PSO controls the direction of position and velocity vectors, whereas the GA modifies the decision vectors using genetic operators $[55,56]$. Several researchers have successfully applied the 
PSO-GA to optimization problems. Mozafar et al. used the PSO-GA to achieve optimal allocations of renewable energy sources and electric vehicle charging stations in smart grids [56]. Yu et al. used the PSO-GA optimal model to estimate the primary energy demand of China [54]. Ghorbani et al. used the PSO-GA to optimize a hybrid wind-PV-battery system [57]. In the PSO-GA, seven parameters-w, $\mathrm{c}_{1}$, $\mathrm{c}_{2}, \mathrm{r}_{1}, \mathrm{r}_{2}, \mathrm{P}_{\mathrm{c}}$, and $\mathrm{P}_{\mathrm{m}}$ are considered to solve the optimization problem. In the foregoing, $\mathrm{w}$ is the coefficient of inertia; $\mathrm{c}_{1}$ and $\mathrm{c}_{2}$ are the two learning coefficients, which are usually set to $1.5 ; \mathrm{n}_{1}$ and $\mathrm{n}_{2}$ are the two random numbers uniformly distributed in the interval $[0,1] ; \mathrm{P}_{c}$ and $\mathrm{P}_{\mathrm{m}}$ are the percentages of the crossover and mutation operators, respectively, in the GA part of the PSO-GA. As an integrated algorithm, the PSO-GA combines the advantages of the GA and PSO but avoids their drawbacks. In addition, the PSO-GA has a stronger and efficient optimization capability than the GA or the PSO alone. The hybrid PSO-GA method has been tested and compared with the GA and the PSO. The results confirm that the PSO-GA has better optimization results than the GA and the PSO [47]. The detailed steps of the hybrid algorithm are as follows:

Step 1. Initialize the parameters for the PSO-GA. The population size is set to 50; maximum number of generations is set to $200 ; c_{1}$ and $c_{2}$ are both set to 1.5 ; maximum particle velocity is set to 5 ; crossover and mutation probabilities are set to 0.8 and 0.3 , respectively.

Step 2. Randomly generate the initial position and velocity vectors of each particle in the population.

Step 3. The parameters of the solar field, coal-fired power system and economic values are encoded, and fitness is calculated.

Step 4. Find the pbest and gbest.

Step 5. Let $\mathrm{i}=1$.

Step 6. $\mathrm{i}=\mathrm{i}+1$. 
Step 7. Update position and velocity vectors.

Step 8. Perform crossover and mutation operations on the population.

Step 9. Recalculate fitness, and update pbest and gbest.

Step 10. Check the stop criterion when the current generation reaches the maximum number of generations or when the fitness value of the population remains constant for 50 iterations. If the criterion is satisfied, then the iteration stops, and the optimization results are delivered; otherwise, return to Step 6.

\section{Case study-results and discussions}

4.1 Input conditions

In this study, the authors consider a supercritical coal-fired power plant with a single-reheat and condensing steam turbine with a capacity of $600 \mathrm{MW}_{\mathrm{e}}$ at the design point. The thermal parameters of the main steam and reheat steam are 566/24.2 and 566/3.6 $\square / \mathrm{MPa}$, respectively. The properties of the bituminous coal are summarized in Table 1 [46]. To maintain the total electricity output constant from the STACP system, the operation in the fuel-saving mode is mainly discussed. The real-time power load of a $600 \mathrm{MW}_{\mathrm{e}}$ unit in China is shown in Fig. 3. Lhasa $\left(29.67^{\circ} \mathrm{N}, 91.13^{\circ} \mathrm{E}\right)$ is selected as the location of the STACP system and the design point of the heliostat field is set as the solar noon on the summer solstice (June 21). The $\mathrm{SM}$ for the basic study is set as 2.0, and $\mathrm{Q}_{\mathrm{de}}$ is set as $68.8 \mathrm{MW}_{\text {th }}$ [45]. The parameters related to the solar field are summarized in Table 2. The annual performance simulation is based on an hourly irradiation and temperature data at the site. To reveal the influence of different solar radiation levels on the performance of the hybrid system, the DNI of a typical meteorological year from Bakersfield, Lhasa, and Beijing are used in this study. The solar resource data for each of the aforementioned location are obtained from SAM. The yearly DNI of these three places are 2157, 1777, 
and $1189 \mathrm{kWh} / \mathrm{m}^{2} /$ year, respectively; the annual DNI distributions of a typical meteorological year are presented in Fig. 4. The ambient temperature and wind speed at Lhasa are shown in Fig. 5. The temperatures of the hot and cold tanks are assumed to be 580 and $350 \square$, respectively, and the TES capacity is chosen as $5 \mathrm{~h}$, which indicates that the thermal capacity is $5 \times 68.8 \mathrm{MWh}_{\mathrm{th}}$; $\mathrm{U}$ is assumed to be $0.4 \mathrm{~W} / \mathrm{m}^{2} \mathrm{~K}$. In this study, the molten salt used is a mixture of $60 \% \mathrm{NaNO}_{3}$ and $40 \% \mathrm{KNO}_{3}$. The thermal properties are calculated based on the following equations:

$$
\begin{gathered}
\rho_{\mathrm{ms}}=2263.72-0.636 \mathrm{~T} \\
\mathrm{c}_{\mathrm{p}}=1396.02+0.172 \mathrm{~T} \\
\lambda=0.391+0.00019 \mathrm{~T}
\end{gathered}
$$

where $\rho_{\mathrm{ms}}$ is the density of molten salt; $c_{\mathrm{p}}$ is the specific heat of molten salt at constant pressure; $\lambda$ is the thermal conductivity of molten salt; $\mathrm{T}$ is the temperature of molten salt.

Table 1. Properties of coal used in this study

\begin{tabular}{lrrrrrrrr}
\hline Items & $\mathrm{A}(\mathrm{wt} \%)$ & $\mathrm{M}(\mathrm{wt} \%)$ & $\mathrm{C}(\mathrm{wt} \%)$ & $\mathrm{H}(\mathrm{wt} \%)$ & $\mathrm{N}(\mathrm{wt} \%)$ & $\mathrm{S}(\mathrm{wt} \%)$ & $\mathrm{O}(\mathrm{wt} \%)$ & $\mathrm{LHV}(\mathrm{kJ} / \mathrm{kg})$ \\
\hline Coal & 23.72 & 25 & 57.5 & 3.11 & 0.99 & 2 & 2.78 & 21,981 \\
\hline
\end{tabular}

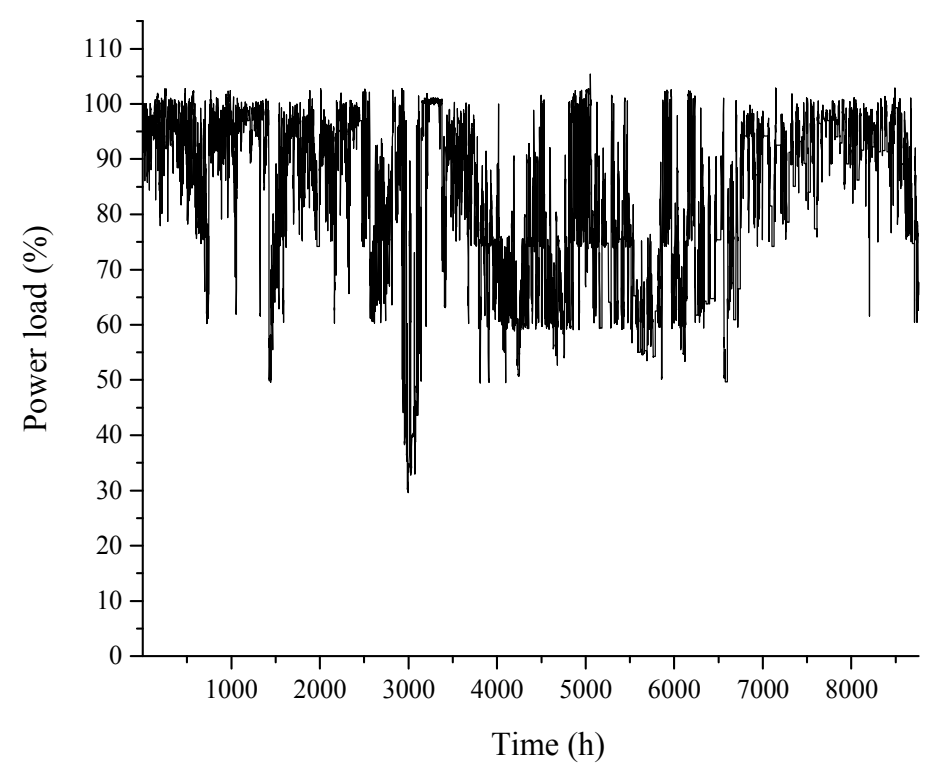

Fig. 3 Real-time power loads of a coal-fired power plant 
Table 2 Solar field basic parameters [58, 59]

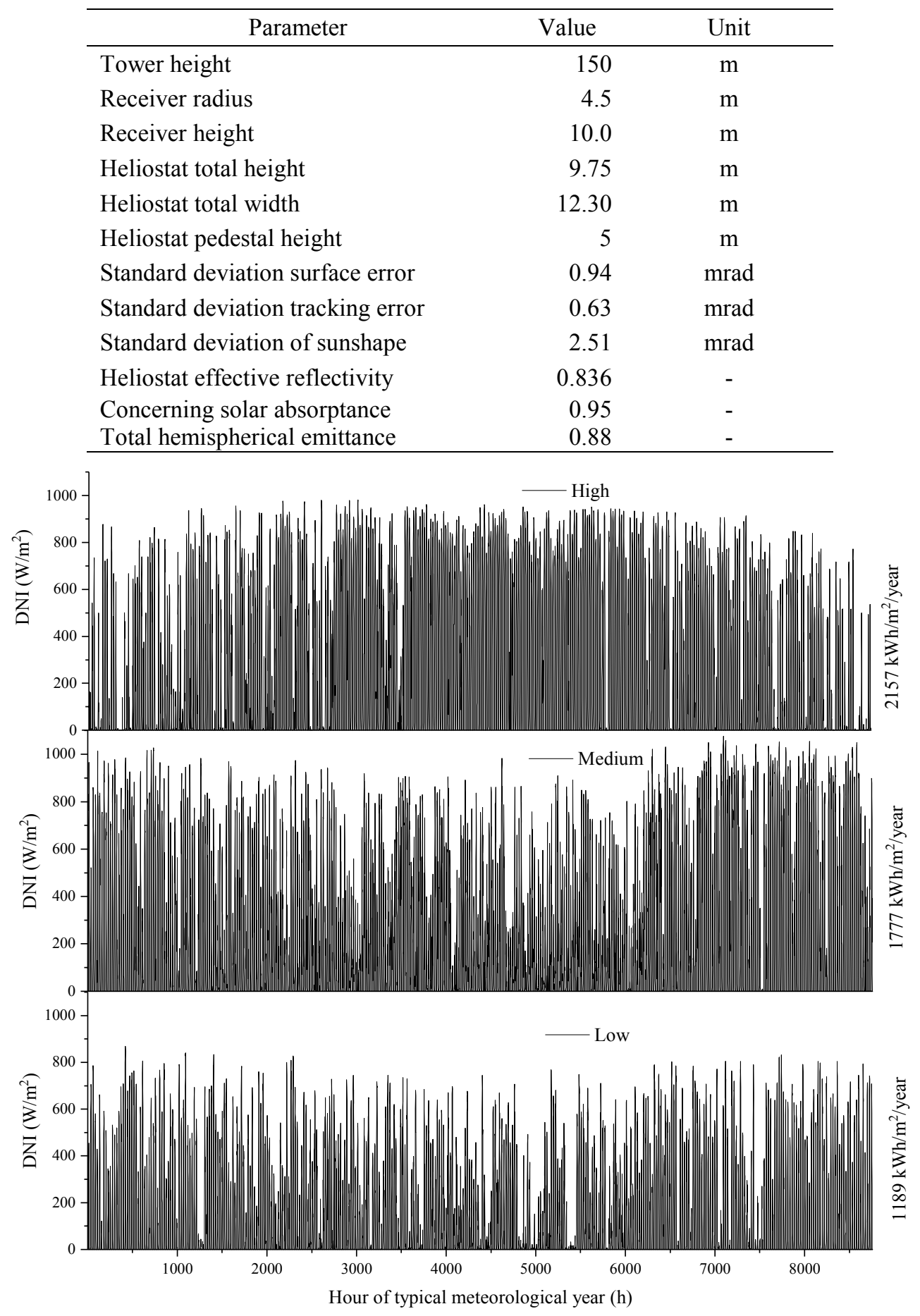

Fig. 4 Annual DNI distributions of a typical meteorological 


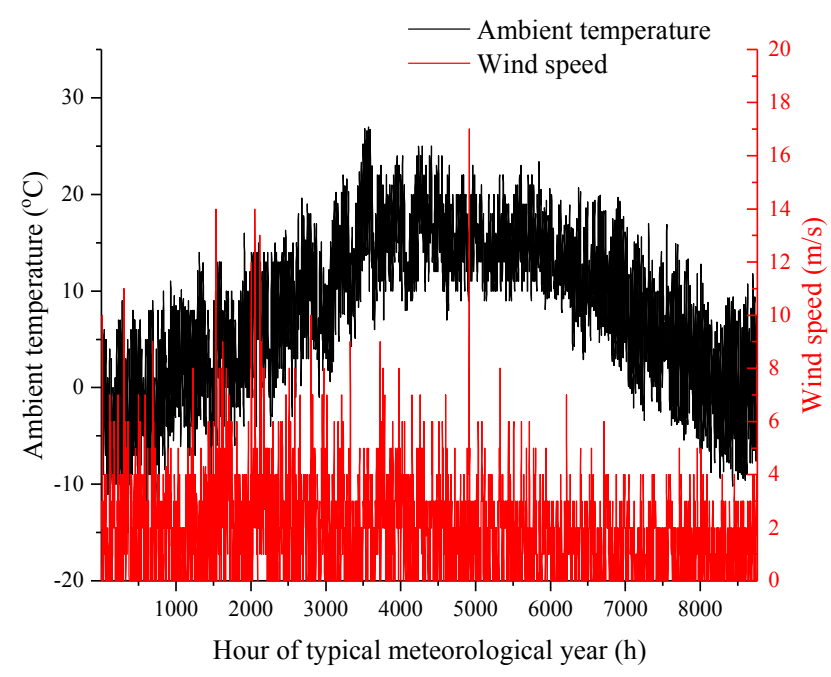

Fig. 5 Ambient temperature and wind speed in Lhasa

The basic economic parameters are summarized in Table 3.

Table 3. Basic economic parameters

\begin{tabular}{|c|c|c|c|}
\hline Parameter & units & Assigned value & Ref \\
\hline \multicolumn{4}{|l|}{ Direct cost (DC) } \\
\hline $600 \mathrm{MW}$ coal-fired power plant & US\$ & 253 million & [3] \\
\hline Heliostat cost & $\mathrm{US} \$ / \mathrm{m}^{2}$ & 126 & [47] \\
\hline Solar tower & US\$ & 8.5 million & {$[47]$} \\
\hline Receiver & US\$ & 21.3 million & [47] \\
\hline Storage cost & $\mathrm{US} \$ / \mathrm{kWh}_{\mathrm{th}}$ & 30 & {$[60]$} \\
\hline Steam generator cost & $\mathrm{US} \$ / \mathrm{kW}_{\mathrm{e}}$ & 300 & {$[60]$} \\
\hline Land cost & $\mathrm{US} \$ / \mathrm{m}^{2}$ & 1.67 & {$[24]$} \\
\hline Contingency & $\%$ of DC & 10 & {$[24]$} \\
\hline Indirect cost & $\%$ of $\mathrm{DC}$ & 18.5 & {$[24]$} \\
\hline O\&M & $\%$ of $\mathrm{CC}$ & 2 & [61] \\
\hline Coal cost & US\$/GJ & $2.32 *$ & [3] \\
\hline $\mathrm{CO}_{2}$ emission penalty cost & $\mathrm{US} \$ / \mathrm{t}$ & 40 & {$[62]$} \\
\hline Operation period & Year & 30 & {$[24]$} \\
\hline Discount percentage & $\%$ & 8 & [24] \\
\hline
\end{tabular}

Table 4 lists the annual performances of a coal-fired power system, which operates on its own, and the STACP system under three different DNI cases (H-DNI, M-DNI, and L-DNI). Because of the fuel- 
saving mode considered in this study, the annual power output is the same in all systems, 4,398 GWh. For the three STACP systems, the H-DNI has the lowest coal consumption (1.204 million tons), and LDNI has the highest coal consumption (1.215 million tons). Compared with the coal-fired power system, the decline in the annual coal consumptions of the H-DNI, M-DNI, and L-DNI are 25,450, 19,870, and $14,170 \mathrm{t}$, respectively; when converted into annual average coal consumption rates, these are 273.64, 274.91, and $276.21 \mathrm{~g} / \mathrm{kWh}$, respectively. Compared with the coal-fired power system, the reductions in annual average coal consumption rates are $5.79,4.52$, and $3.22 \mathrm{~g} / \mathrm{kWh}$, respectively. The H-DNI case also has the lowest annual $\mathrm{CO}_{2}$ emission (3.405 million tons) and L-DNI the highest annual $\mathrm{CO}_{2}$ emission, (3.431 million tons). Moreover, the annual $\mathrm{CO}_{2}$ emission rates of H-DNI, M-DNI, and L-DNI are 774.17, 777.76, and $780.04 \mathrm{~g} / \mathrm{kWh}$, respectively; compared with the coal-fired power system, the reductions in the annual $\mathrm{CO}_{2}$ emission rate are $16.37,12.78$, and $10.50 \mathrm{~g} / \mathrm{kWh}$, respectively. The annual solar generating power of H-DNI, M-DNI, and L-DNI are 100.72, 79.18, and $65.13 \mathrm{GWh}$, respectively. The H-DNI exhibits the highest annual solar generating power because it collects and uses more solar energy than the other two STACP cases. However, interestingly, the L-DNI shows the highest annual solar-toelectricity efficiency of $23.59 \%$, and the annual solar-to-electricity efficiency of M-DNI and H-DNI are 23.18 and $19.18 \%$, respectively. This is because more solar energy is discarded in the M-DNI and H-DNI because of the limit in the TES capacity. In all the STACP systems, the H-DNI has the lowest LCOE, whereas the L-DNI has the highest LCOE. The LCOE of H-DNI, M-DNI, and L-DNI are 6.37, 6.40, and $6.41 \notin / \mathrm{kWh}$, respectively. Compared with the coal-fired power system, the increase in LCOE of H-DNI, M-DNI, and L-DNI are $0.19,0.21$ and $0.23 \phi / \mathrm{kWh}$, respectively.

Table 4. Annual performance of the STACP system in three different DNI scenarios assuming deployment of power tower systems to augment coal generators 


\begin{tabular}{|c|c|c|c|c|c|}
\hline & units & $\begin{array}{l}\text { Coal- } \\
\text { fired }\end{array}$ & $\begin{array}{l}\text { High } \\
\text { DNI }\end{array}$ & $\begin{array}{l}\text { Medium } \\
\text { DNI }\end{array}$ & $\begin{array}{l}\text { Low } \\
\text { DNI }\end{array}$ \\
\hline Annual power output & GWh & \multicolumn{4}{|c|}{4398} \\
\hline Annual standard coal consumption & $10^{3} \mathrm{t}$ & 1229.0 & 1203.5 & 1209.1 & 1214.8 \\
\hline \multicolumn{6}{|c|}{ Annual average standard coal consumption } \\
\hline rate & $\mathrm{g} / \mathrm{kWh}$ & 279.43 & 273.64 & 274.91 & 276.21 \\
\hline Solar generating power & GWh & - & 100.72 & 79.18 & 65.13 \\
\hline Annual solar-to-electricity efficiency & $\%$ & - & 19.88 & 23.18 & 23.59 \\
\hline Annual $\mathrm{CO}_{2}$ emission & $10^{3} \mathrm{t}$ & 3476.8 & 3404.8 & 3420.6 & 3430.6 \\
\hline Annual $\mathrm{CO}_{2}$ emission rate & $\mathrm{g} / \mathrm{kWh}$ & 790.54 & 774.17 & 777.76 & 780.04 \\
\hline LCOE & $\notin / \mathrm{kWh}$ & 6.18 & 6.37 & 6.40 & 6.41 \\
\hline
\end{tabular}

In order to explore the influence of TES capacity on the solar generating power and solar-toelectricity efficiency, the different TES capacities (specified in hours of solar operation at rated-load) are considered, as shown in Fig. 6. For the H-DNI and M-DNI, the annual solar generating power gradually increases with the increase in TES capacity; however, the rate of increase gradually decreases. When the TES capacity changes from 0 to $17 \mathrm{~h}$, the solar generating power of H-DNI increases from 69.42 to 115.17 GWh and the solar generating power of M-DNI increases from 55.65 to $81.74 \mathrm{GWh}$. However, in the L-DNI, the solar generating power first increases and then decreases with the increase in TES capacity; the solar-generated power reaches a maximum of $65.78 \mathrm{GWh}$ at $11 \mathrm{~h}$. This is because when the TES capacity is reached $11 \mathrm{~h}$, all the solar energy collected by the receiver would be consumed by the STACP system, and any further increase in the TES capacity merely leads to greater energy loss. Moreover, with the increase in TES storage, the solar-to-electricity efficiency of the H-DNI increases from 13.7 to $22.73 \%$ and the solar-to-electricity efficiency of the M-DNI increases from 16.29 to $23.93 \%$. In the L-DNI, the solar-to-electricity efficiency first peaks to $23.82 \%$ and then decreases to $23.80 \%$. When the TES capacity is $>8 \mathrm{~h}$, the solar-to-electricity efficiency of M-DNI is the highest, and when the TES capacity is $\leq 8 \mathrm{~h}$, the solar-to-electricity efficiency of L-DNI is the highest. 


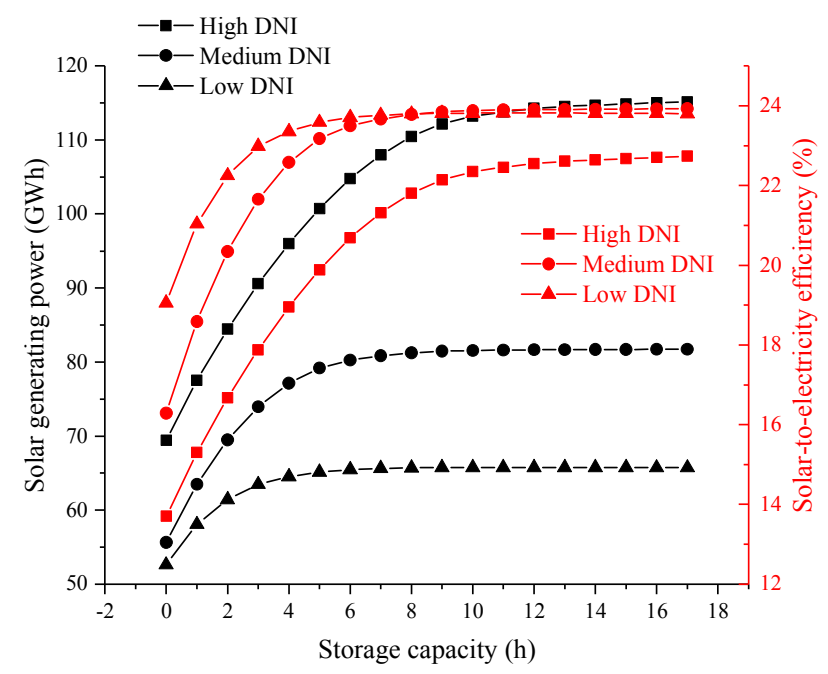

Fig.6 Variations of $P_{\text {solar }}$ and $\eta_{\text {solar }}$ with the change in storage capacity

4.3 Optimization results of thermal storage capacity

In this section, the PSO-GA optimization algorithm is applied to optimize the TES capacity to obtain the lowest LCOE under different solar multiples; the optimization results are shown in Fig. 7. When the SM increases from 1.0 to 3.0, for the H-DNI, the optimal TES capacity increases from 0 to $6.7 \mathrm{~h}$; for the M-DNI, the optimal TES capacity increases from 0 to $4.4 \mathrm{~h}$; and for the L-DNI, the optimal TES capacity increases from 0 to $2.2 \mathrm{~h}$. Fig. 8 shows the lowest LCOE of the STACP system and the solar field (and solar plant components) under different solar multiples. The LCOE of the STACP system increases with the SM. This is because as the SM increases, more solar energy would be rejected, leading to the decrease in solar-to-electricity efficiency (Fig. 10) and the increase in LCOE. The LCOE of the solar field has the same trend as that of the solar-alone thermal power system, which first decreases and then increases as the SM increases. For the H-DNI, the LCOE of the solar field has the lowest value when the SM is 2.4; for the M-DNI and L-DNI, the LCOE of the solar field has the lowest value when SM is 2.6. 


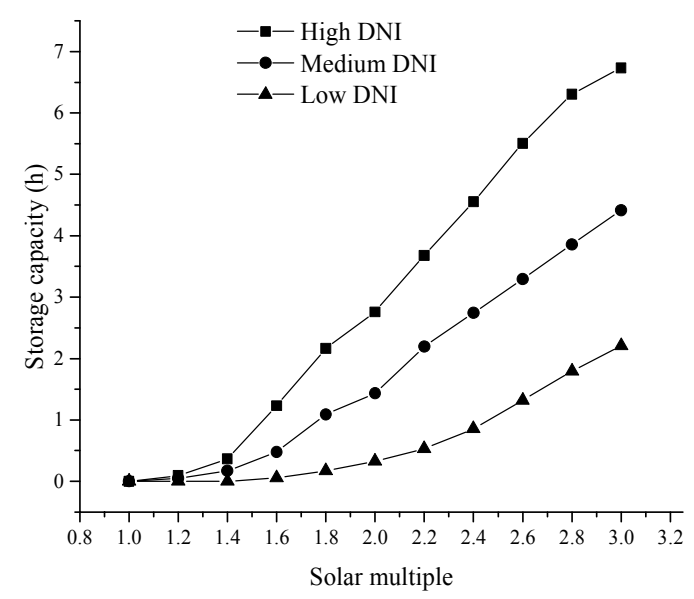

Fig. 7 Optimal thermal storage capacity under different solar multiples

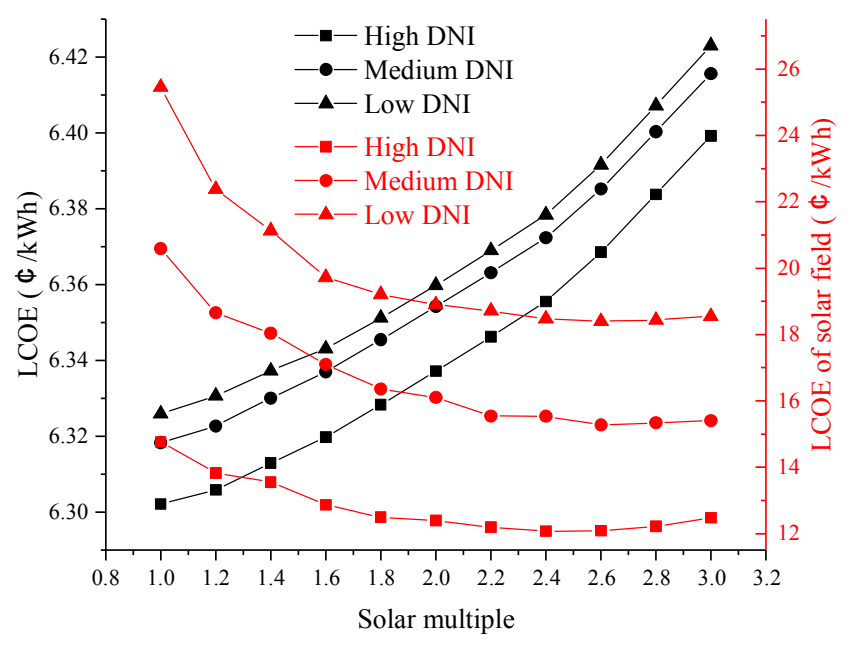

Fig. 8 Variation of LCOE under different solar multiples

Fig. 9 shows the change in the annual $\mathrm{CO}_{2}$ emission rate and annual average coal consumption rate.

With the increase in $\mathrm{SM}$, the annual $\mathrm{CO}_{2}$ emission and annual average coal consumption rates decrease.

As the SM increases from 1.0 to 3.0, for the $\mathrm{H}-\mathrm{DNI}$, the annual $\mathrm{CO}_{2}$ emission rate decreases from 782.27

to $770.29 \mathrm{~g} / \mathrm{kWh}$; for the M-DNI, from 784.65 to $774.93 \mathrm{~g} / \mathrm{kWh}$; for the L-DNI, from 785.77 to 778.15

$\mathrm{g} / \mathrm{kWh}$. As the SM increases from 1.0 to 3.0, the changes in the annual average coal consumption rates for H-DNI, M-DNI, and L-DNI are 4.23, 3.44, and $2.69 \mathrm{~g} / \mathrm{kWh}$, respectively. Fig. 10 shows the changes in the solar generating power and solar-to-electricity efficiency. As the SM increases, the solar generating power increases, but the solar-to-electricity efficiency decreases. As the SM increases from 1.0 to 3.0, for the H-DNI, the solar generating power increases from 51.8 to $124.33 \mathrm{GWh}$; for the M-DNI, it 
increases from 37.2 to $96.3 \mathrm{GWh}$; for the L-DNI, it increases from 30.1 to $76.6 \mathrm{GWh}$. As the SM increases, the solar-to-electricity efficiency decreases from 21.80 to $15.00 \%$ for the H-DNI; from 23.18 to $17.22 \%$ for the M-DNI; from 23.19 to $16.94 \%$ for the L-DNI. Results indicate that the change in SM has more influence on the H-DNI than on the M-DNI and L-DNI because more surplus energy is discarded.

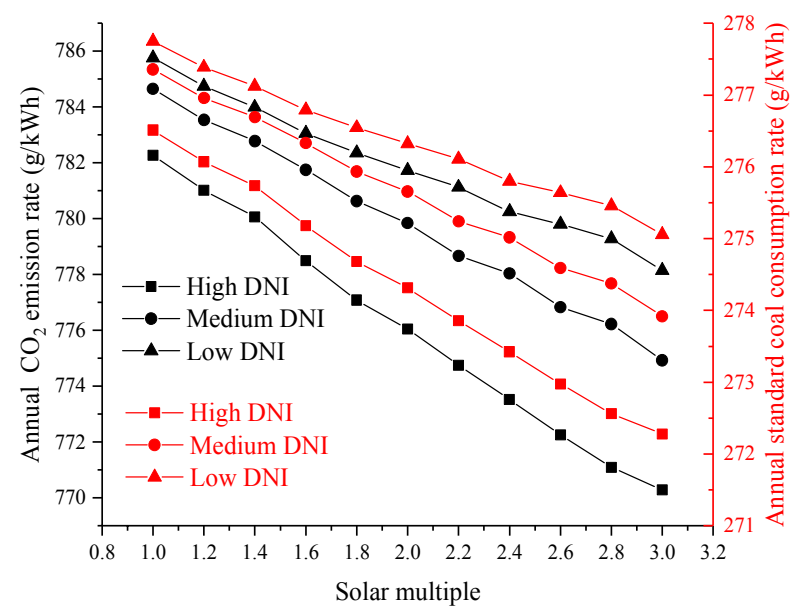

Fig. 9 Variations in the annual average coal consumption rate and annual $\mathrm{CO}_{2}$ emission rate under

different solar multiples

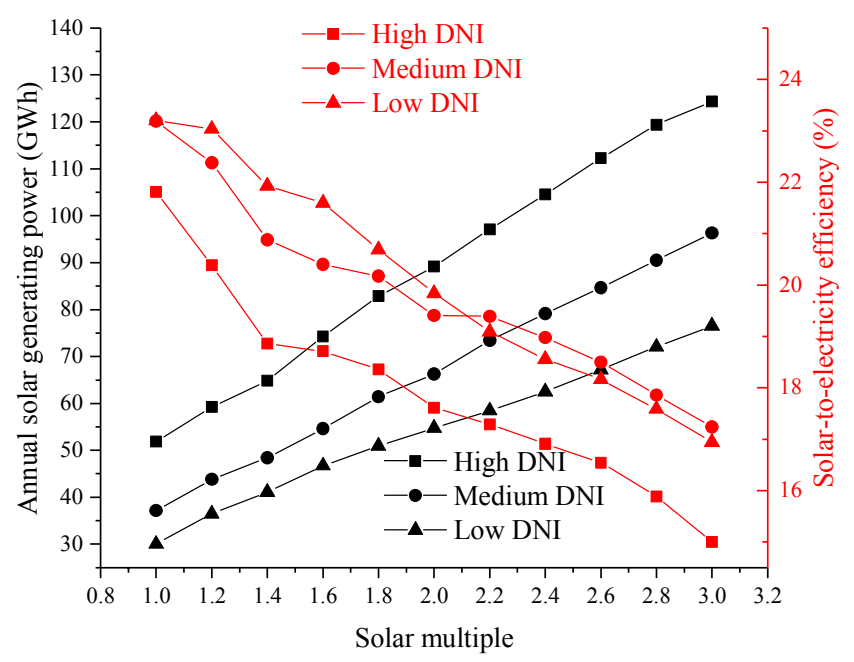

Fig. 10 Variations in the solar generating power and solar-to-electricity efficiency under different solar multiples

\subsection{Sensitivity analysis}


In this section, the influence of coal price, $\mathrm{CO}_{2}$ emission penalty cost, thermal storage cost and heliostat cost on the optimal TES hour and LCOE are discussed.

\subsubsection{Influence of coal price}

Fig. 11a-11c show the influence of coal price on the optimal TES capacity and LCOE under the high DNI, medium DNI, and low DNI, when coal price changes from 69.37 to 109.37 US\$/t. With the increase in coal price, the optimal TES capacity normally rises and the LCOE shows a linear upward trend. For the H-DNI, the LCOE increases by $0.277,0.274$, and $0.272 \phi / \mathrm{kWh}$ for every $10 \mathrm{US} \$ / \mathrm{t}$ increase in coal price when the SM is 1.0, 2.0, and 3.0, respectively. For the M-DNI, the LCOE increases by 0.277, 0.276 , and $0.274 \phi / \mathrm{kWh}$ for every $10 \mathrm{US} \$ / \mathrm{t}$ addition to the coal price when the SM is 1.0, 2.0 and 3.0, respectively. For the L-DNI, the LCOE increases by $0.278,0.276$, and $0.275 \phi / \mathrm{kWh}$ for every $10 \mathrm{US} \$ / \mathrm{t}$ addition to the coal price when the SM is 1.0, 2.0 and 3.0. Moreover, the LCOE in the original coal-fired power system increases from 5.905 to $7.023 \phi / \mathrm{kWh}$, and the LCOE increases by $0.294 \not / \mathrm{kWh}$ for every $10 \mathrm{US} \$ / \mathrm{t}$ addition to the coal price. Therefore, the gap between the LCOEs of the STACP system and the original coal-fired system decrease with an increase in coal price, which indicates that the STACP system is more profitable as the coal price increases.

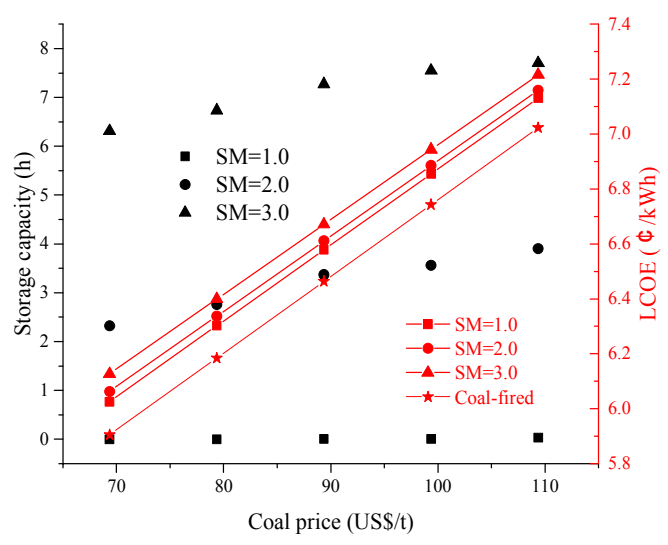



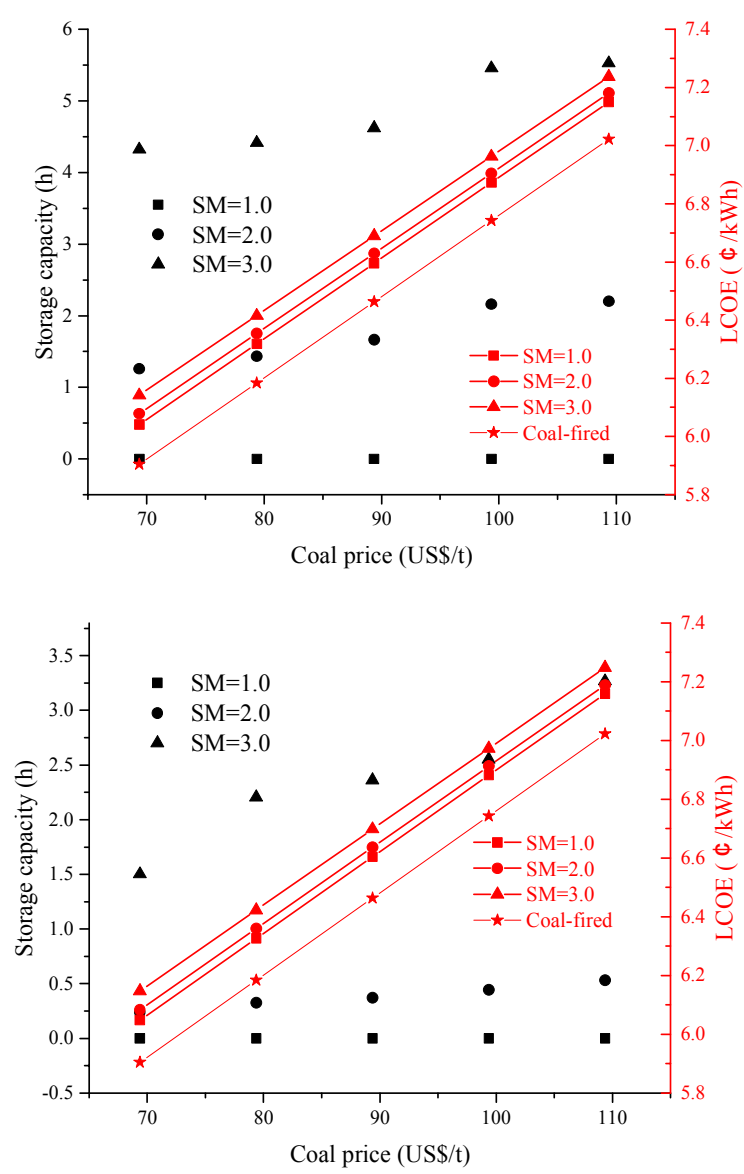

Fig. 11 Influence of coal price on optimal thermal storage capacity and LCOE under (a) high DNI, (b)

medium DNI, and (c) low DNI

\subsubsection{Influence of $\mathrm{CO}_{2}$ emission penalty cost}

The influences of $\mathrm{CO}_{2}$ emission penalty cost on the optimal TES capacity and LCOE (in the high, medium, and low DNIs) when $\mathrm{CO}_{2}$ emission penalty cost changes from 30 and to $50 \mathrm{US} \$ / \mathrm{t}$ are shown in Fig. 12a-12c. With the increase in $\mathrm{CO}_{2}$ emission penalty cost, the optimal TES capacity normally increases and the LCOE exhibits a linear upward trend. For the H-DNI, the LCOE increases by 0.782 , $0.776 \varnothing / \mathrm{kWh}$, and $0.770 \notin / \mathrm{kWh}$ for every $10 \mathrm{US} \$ / \mathrm{t}$ increase in the $\mathrm{CO}_{2}$ emission penalty cost when SM is $1.0,2.0$ and 3.0, respectively. For the M-DNI, the LCOE increases by $0.785,0.780$, and $0.775 \varnothing / \mathrm{kWh}$ for every $10 \mathrm{US} \$ / \mathrm{t}$ addition to the $\mathrm{CO}_{2}$ emission penalty cost when SM is 1.0, 2.0 and 3.0, respectively. For the L-DNI, the coal price increases by $0.786,0.782$, and $0.778 \phi / \mathrm{kWh}$ for every $10 \mathrm{US} \$ / \mathrm{t}$ addition to 
the $\mathrm{CO}_{2}$ emission penalty cost when SM is $1.0,2.0$ and 3.0, respectively. In addition, the LCOE of the original coal-fired power system increases from 5.394 to $6.975 \not / \mathrm{kWh}$; the LCOE increases by $0.791 ф / \mathrm{kWh}$ for every $10 \mathrm{US} \$ / \mathrm{t}$ addition to the $\mathrm{CO}_{2}$ emission penalty cost. Therefore, the gap between the LCOEs of the STACP system and the original coal-fired system decreases with the increase in the $\mathrm{CO}_{2}$ emission penalty cost. This indicates that the STACP system is more profitable when the $\mathrm{CO}_{2}$ emission penalty cost increases.

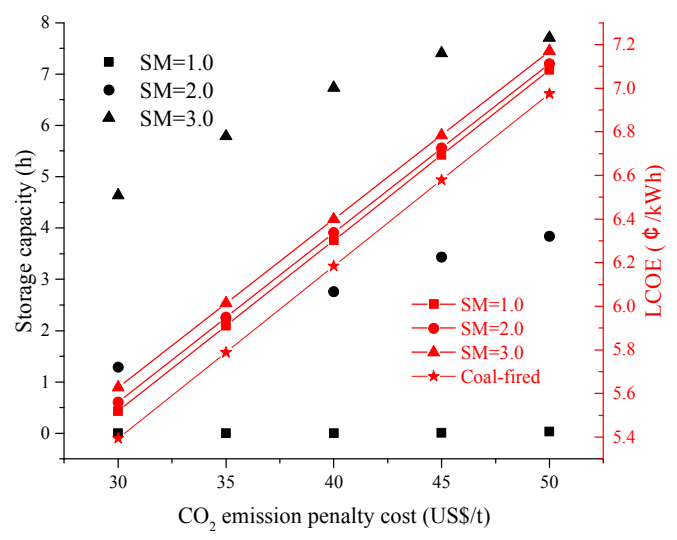

b

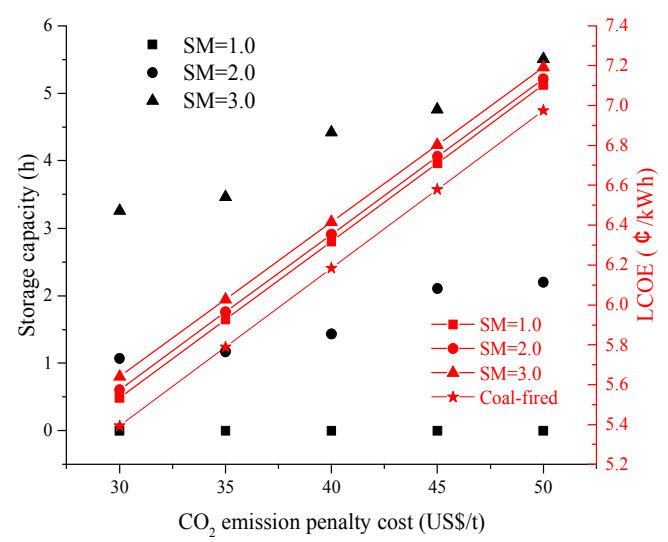




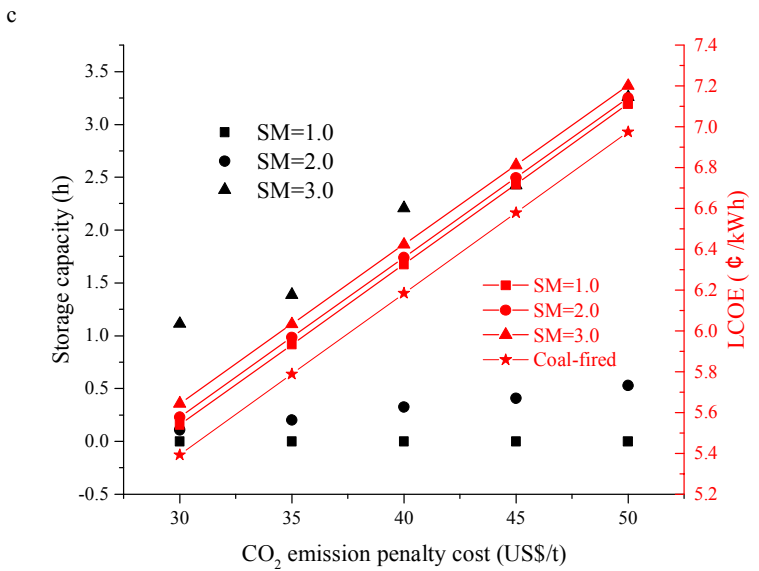

Fig. 12 Influence of $\mathrm{CO}_{2}$ emission penalty cost on optimal thermal storage capacity and LCOE under

(a) high DNI, (b) medium DNI, and (c) low DNI

\subsubsection{Influence of thermal storage cost}

The influences of thermal storage cost on the optimal TES capacity and LCOE (under high DNI, medium DNI, and low DNI) when the thermal storage cost changes from 26 to $34 \mathrm{US} \$ / \mathrm{kWh}$ th are shown in Fig, 13a-13c. With the increase in thermal storage cost, the optimal TES capacity normally exhibits a downward trend, and the LCOE shows a slight linear upward trend. For the H-DNI, as the thermal storage cost increases, the LCOE only slightly rises around 6.30 and $6.34 \not / \mathrm{kWh}$ when the SM is 1.0 and 2.0, respectively. When the SM is 3.0 , the LCOE increases by $0.015 \notin / \mathrm{kWh}$ for every $10 \mathrm{US} \$ / \mathrm{kWh}$ th addition to the thermal storage cost. For the M-DNI, the LCOE slightly rises around 6.32 and $6.35 \phi / \mathrm{kWh}$ when the SM is 1.0 and 2.0 , respectively. When the SM is 3.0 , the LCOE increases by $0.010 \phi / \mathrm{kWh}$ for every $10 \mathrm{US} \$ / \mathrm{kWh}_{\text {th }}$ addition to the thermal storage cost. For the L-DNI, the LCOE slightly rises around 6.33 and $6.36 \notin / \mathrm{kWh}$ when SM is 1.0 and 2.0 , respectively. When the SM is 3.0 , the LCOE increases by $0.005 \phi / \mathrm{kWh}$ for every $10 \mathrm{US} \$ / \mathrm{kWh}_{\mathrm{th}}$ addition to the thermal storage cost. because there is no energy storage system in the original coal-fired power system, the LCOE in this power system remainss stable at $6.184 \phi / \mathrm{kWh}$ with the change in thermal storage cost. Therefore, the gap between the LCOEs of the STACP system and the original coal-fired system decreases when the thermal storage cost is reduced. 
This indicates that the STACP system is more profitable when the thermal storage cost decreases.
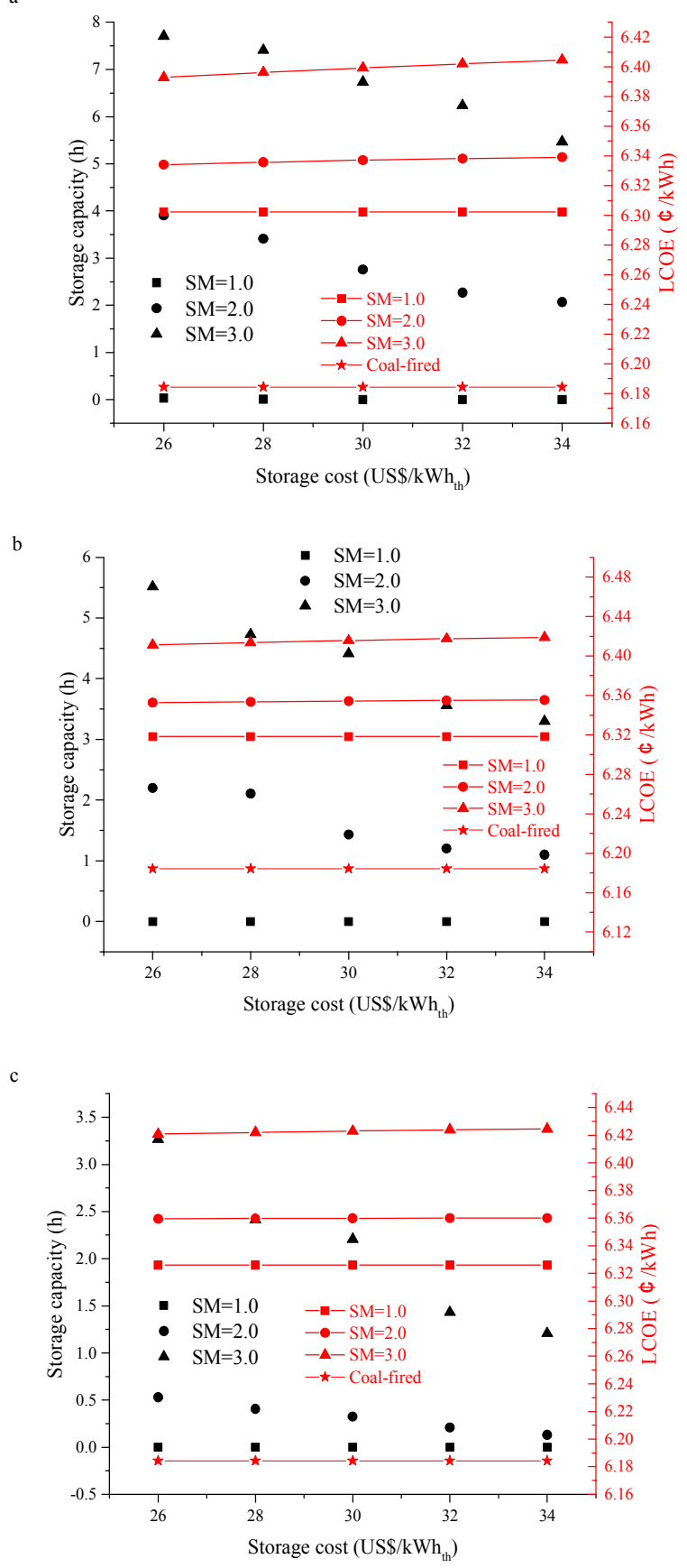

Fig. 13 Influence of thermal storage system cost on optimal thermal storage capacity and LCOE under

(a) high DNI, (b) medium DNI, and (c) low DNI

\subsubsection{Influence of heliostat cost}

Fig. 14a-14c show the influences of heliostat cost on the optimal TES capacity and LCOE (under high DNI, medium DNI and low DNI) when the heliostat cost changes from 86 to $166 \mathrm{US} \$ / \mathrm{m}^{2}$. With the 
increase in the heliostat cost, the optimal TES capacity remains basically unchanged, and the LCOE exhibits a linear upward trend. For the H-DNI, the optimal TES capacities are 0, 2.76, and $6.73 \mathrm{~h}$ when the SM is 1.0, 2.0 and 3.0, respectively; the LCOE increases by $0.03,0.07$, and $0.10 \varnothing / \mathrm{kWh}$ when the $\mathrm{SM}$ is 1.0, 2.0 and 3.0, respectively. For the M-DNI, the optimal TES capacities are $0,1.43$ and $4.42 \mathrm{~h}$ when the SM is 1.0, 2.0 and 3.0, respectively; the LCOE increases by $0.03,0.07$, and $0.11 \notin / \mathrm{kWh}$ when the SM is 1.0, 2.0 and 3.0, respectively. For the L-DNI, the optimal TES capacities are $0,0.33$, and 2.21 $\mathrm{h}$ when the SM is 1.0, 2.0 and 3.0, respectively; the LCOE increases by $0.03,0.06$, and $0.11 \notin / \mathrm{kWh}$ when the $\mathrm{SM}$ is 1.0, 2.0 and 3.0, respectively. As there is no heliostat field in the original coal-fired power system, the LCOE in this power system remains stable at $6.184 \phi / \mathrm{kWh}$. Therefore, the gap between the LCOEs of the STACP system and the original coal-fired system decreases when the heliostat cost declines. This indicates that the STACP system is more profitable when the heliostat cost decreases.

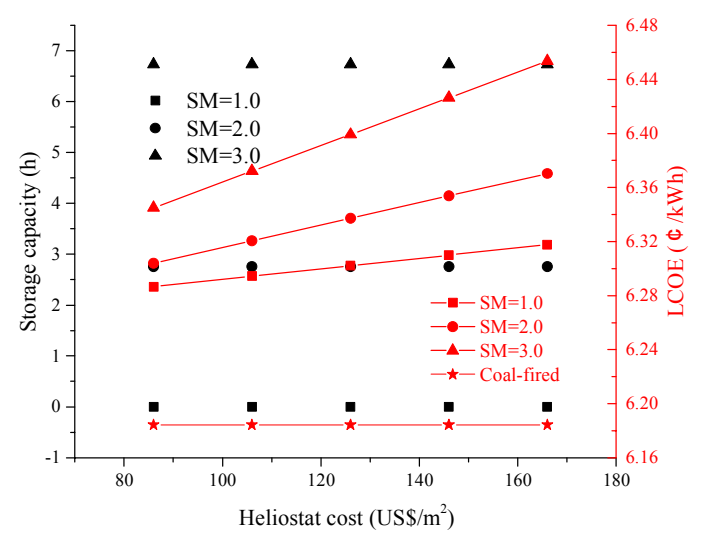

b

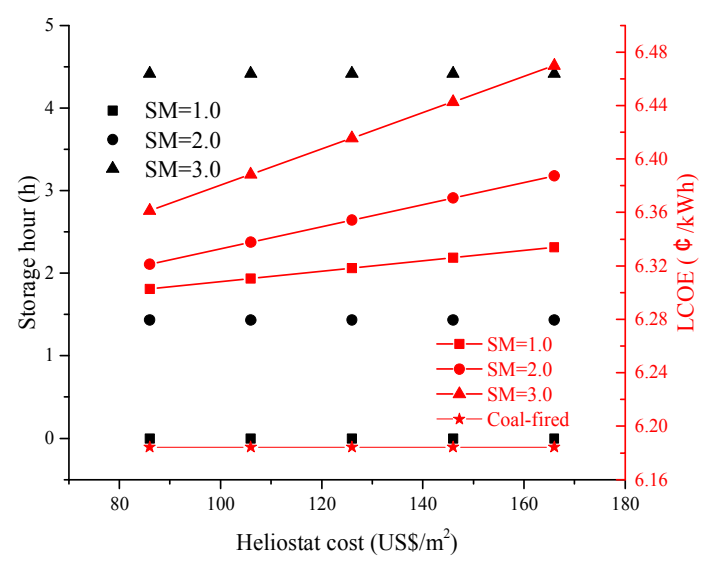




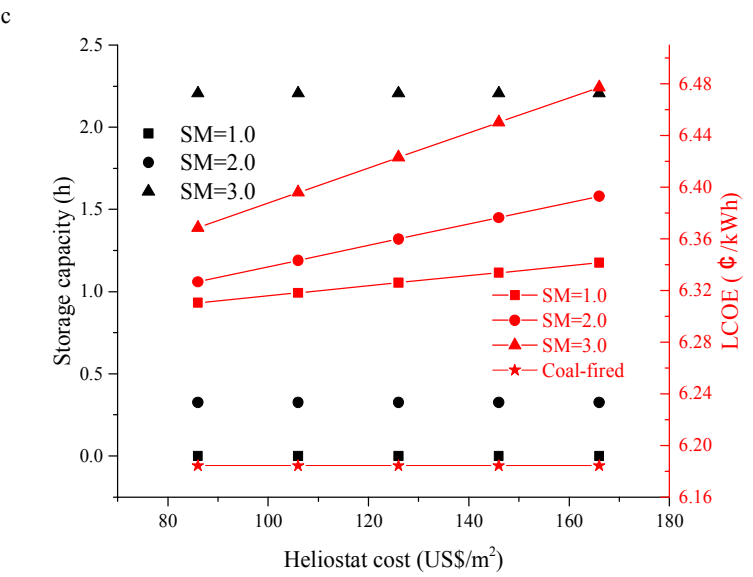

Fig. 14 Influence of heliostat cost on optimal thermal storage capacity and LCOE under (a) high DNI, (b) medium DNI, and (c) low DNI

\section{Conclusions}

In this study, the annual performance of the STACP system has been investigated, and the TES capacity has been optimized to obtain the lowest LCOE. This quantitative analysis is comprehensively performed on a $600 \mathrm{MW}_{\mathrm{e}}$ supercritical coal-fired power plant. The results show that in comparison with the coal-fired power system, the reduction in annual average coal consumption rate of the STACP system with the high DNI, medium DNI, and low DNI are 5.79, 4.52 and $3.22 \mathrm{~g} / \mathrm{kWh}$, respectively, and the reductions in the annual $\mathrm{CO}_{2}$ emission rate are $16.37,12.78$, and $10.50 \mathrm{~g} / \mathrm{kWh}$, respectively. At a minimum, the annual coal consumption and $\mathrm{CO}_{2}$ emissions can be reduced by over 14,000 $\mathrm{t}$ and 46,000 $\mathrm{t}$, respectively. In addition, the LCOE of the STACP system with high DNI, medium DNI, and low DNI are $6.37,6.40$ and $6.41 \phi / \mathrm{kWh}$, respectively. The discussion on the influence of storage capacity indicates that with the increase in storage capacity from 0 to $17 \mathrm{~h}$, the solar generating power and solar-toelectricity efficiency of the STACP system, with high DNI and medium DNI, exhibit an upward trend, whereas those of the STACP system with a low DNI first increases and then slightly decreases. In terms of the optimization of the TES capacity, with the increase in the SM, the optimal TES capacity also increases; with the SM is increased from 1.0 to 3.0, the lowest LCOE of the STACP system with the 
high, medium and low DNIs increases by $0.097,0.098$, and $0.097 £ / \mathrm{kWh}$, respectively. The sensitivity analysis shows that the change in economic parameters (coal price, $\mathrm{CO}_{2}$ emission penalty cost, thermal storage cost, and heliostat cost) has more influence on the STACP system with the high DNI than on the other two systems. Moreover, the thermal storage cost has the most important influence on the optimal TES capacity, whereas the heliostat cost has a minor effect on the optimal TES capacity. The $\mathrm{CO}_{2}$ emission penalty cost has the most significant influence on the optimal LCOE, whereas the thermal storage cost has practically no influence on the optimal LCOE.

\section{Acknowledgments}

The research work is supported by National Major Fundamental Research Program of China (No. 2015CB251505), China National Natural Science Foundation (No. 51776063), the Fundamental Research Funds for the Central Universities (2016YQ04), China Scholarship Council and Cranfield University.

\section{Appendix A. Calculation of heliostat field efficiency}

A.1 Preliminary heliostat field generation

A radial staggered layout of the heliostat field is used in this model. In the radial staggered configuration, the adjacent circles of heliostat mirrors do not have the same azimuth angles that can significantly improve the shadowing and blocking factor. The variables that are used to define the heliostat field layout are shown in Fig. A-1. 


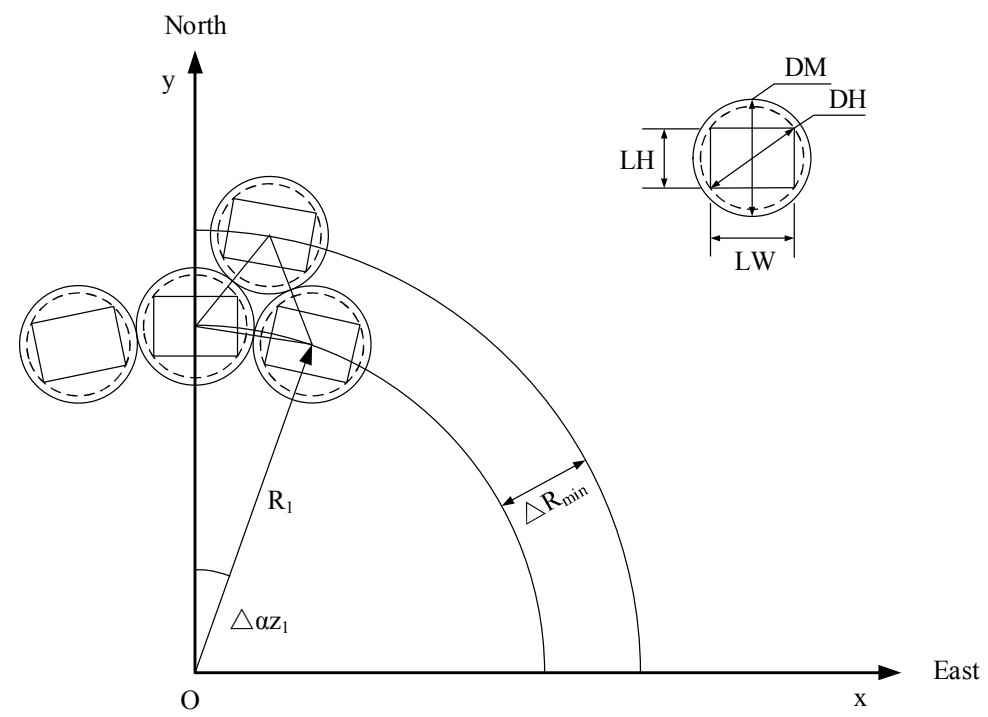

Fig. A-1 Fundamental definitions in the heliostat field

In Fig. A-1, DM is the distance between the center of two contiguous heliostats; this distance can be obtained by the following:

$$
\mathrm{DM}=\mathrm{DH}+\operatorname{desp}
$$

where DH is the diagonal of heliostat (m); desp is the additional separation distance (m). They can be calculated by the following:

$$
\begin{gathered}
\mathrm{DH}=\sqrt{1+\mathrm{w}^{2}} \cdot \mathrm{LH} \\
\operatorname{desp}=\mathrm{x} \cdot \mathrm{LH} \\
\mathrm{w}=\frac{\mathrm{LW}}{\mathrm{LH}}
\end{gathered}
$$

where LH and LW are the height and width of the heliostat (m), respectively; w is the ratio of the width to the height of the heliostat; $\mathrm{x}$ is the optimizing parameter of desp, which can be used to control the azimuthal spacing between two contiguous heliostats.

Based on the above equations, the minimum radial increment can be calculated as follows:

$$
\begin{aligned}
& \Delta \mathrm{R}_{\min }=\mathrm{DM} \cdot \cos 30^{\circ}-\mathrm{h} \\
& \mathrm{h}=\mathrm{R}_{1}-\sqrt{\mathrm{R}_{1}^{2}-\left(\mathrm{DM}^{2} / 4\right)}
\end{aligned}
$$


where $R_{1}$ is the radius of the first row (m). Because of the usual large value of $R_{1}$ in relation to DM, $h$ can be neglected. Therefore, $\Delta \mathrm{R}_{\min }$ can be obtained by the following:

$$
\Delta \mathrm{R}_{\min }=\mathrm{DM} \cdot \cos 30^{\circ}
$$

To optimize the radial distance in different zones (consider three zones as an example), an optimizing parameter is introduced in Eq. (A-7). Thus, the modified equation of radial distance can be obtained as follows:

$$
\Delta \mathrm{R}_{\mathrm{i}}=\mathrm{y}_{\mathrm{i}} \cdot \mathrm{DM} \cdot \cos 30^{\circ} \quad(\mathrm{i}=1,2,3)
$$

where $\Delta \mathrm{R}_{\mathrm{i}}$ is the radial distance in different zones $(\mathrm{m}) ; \mathrm{y}_{\mathrm{i}}$ is the optimizing parameter of radial distance in different zones.

The azimuth angular spacing between adjacent heliostats in the first zone, which remains the same in the zone, can be calculated by the following:

$$
\Delta \alpha \mathrm{z}_{1}=2 \operatorname{asin}\left[\mathrm{DM} / 2 \mathrm{R}_{1}\right] \cong \mathrm{DM} / \mathrm{R}_{1}
$$

where $\Delta \alpha z_{1}$ is the azimuth angular spacing between the adjacent heliostats in the first zone (rad).

Because of the radial stagger configuration, the length of the azimuth spacing (in meters) gradually increases as the radius of the row increases. Any zone would be complete when an additional heliostat between the adjacent heliostats can be placed in the same row. Therefore, the azimuth angular spacing of the second zone $\left(\Delta \alpha z_{2}\right)$ and the third zone $\left(\Delta \alpha z_{3}\right)$ should be as follows:

$$
\begin{aligned}
& \Delta \alpha z_{2}=\Delta \alpha z_{1} / 2=D M / R_{2} \Rightarrow R_{2} \cong 2\left(D M / \Delta \alpha z_{1}\right)=2 R_{1} \\
& \Delta \alpha z_{3}=\Delta \alpha z_{1} / 4=D M / R_{3} \Rightarrow R_{3} \cong 4\left(D M / \Delta \alpha z_{1}\right)=4 R_{1}
\end{aligned}
$$

Because the radial distances in different zones remain the same, the number of rows in different zones can be calculated as follows:

$$
\operatorname{Nrows}_{1}=\left(\mathrm{R}_{2}-\mathrm{R}_{1}\right) / \Delta \mathrm{R}_{1} \cong \operatorname{round}\left(\mathrm{R}_{1} / \Delta \mathrm{R}_{1}\right)
$$




$$
\begin{aligned}
& \operatorname{Nrows}_{2}=\left(\mathrm{R}_{3}-\mathrm{R}_{2}\right) / \Delta \mathrm{R}_{2} \cong \operatorname{round}\left(2 \mathrm{R}_{1} / \Delta \mathrm{R}_{2}\right) \\
& \text { Nrows }_{3}=\left(\mathrm{R}_{4}-\mathrm{R}_{3}\right) / \Delta \mathrm{R}_{3} \cong \operatorname{round}\left(4 \mathrm{R}_{1} / \Delta \mathrm{R}_{3}\right)
\end{aligned}
$$

where $\mathrm{Nrows}_{1}, \mathrm{Nrows}_{2}$, and $\mathrm{Nrows}_{3}$ are the number of rows in the three different zones; round indicates that the quotient is rounded off to the next lower integer because $\mathrm{Nrows}_{\mathrm{i}}$ is an integer.

The number of heliostats in each row in different zones can be obtained as follows:

$$
\begin{gathered}
\text { Nhel }_{1}=2 \pi / \Delta \alpha z_{1}=2 \pi R_{1} / D M \Rightarrow R_{1}=\left(D M \cdot \text { Nhel }_{1}\right) / 2 \pi \\
\text { Nhel }_{2}=4 \pi R_{1} / \mathrm{DM} \\
\mathrm{Nhel}_{3}=8 \pi \mathrm{R}_{1} / \mathrm{DM}
\end{gathered}
$$

Based on Eq. (A-15), it can be concluded that $R_{1}$ is a function of DM and $N_{h e l}$. Thus, $R_{1}$ can be controlled by varying the $\mathrm{DM}$ and $\mathrm{Nhel}_{1}$ during the optimization process.

The land area of the heliostat field can be calculated by the following:

$$
\text { Area }=\pi\left(\mathrm{R}_{\text {last }}+0.5 \mathrm{DM}\right)^{2}
$$

where Area is the land area covered by the heliostat field $\left(\mathrm{m}^{2}\right) ; \mathrm{R}_{\text {last }}$ is the radius of the last row in the heliostat (m).

\section{A.2 Optical efficiency calculation}

Based on the Sandia nomenclature, the instantaneous optical efficiency of a heliostat is defined as follows:

$$
\eta(x, y, t)=\rho \cdot \cos (x, y, t) f_{a t}(x, y) f_{s b}(x, y, t) f_{\text {int }}(x, y, t)
$$

where $\rho$ is the reflectivity of the heliostats; $\cos (\mathrm{x}, \mathrm{y}, \mathrm{t})$ is the cosine factor; $\mathrm{f}_{\mathrm{at}}(\mathrm{x}, \mathrm{y})$ is the atmospheric attenuation factor; $\mathrm{f}_{\mathrm{sb}}(\mathrm{x}, \mathrm{y}, \mathrm{t})$ is the shadowing and blocking factor; $\mathrm{f}_{\text {int }}(\mathrm{x}, \mathrm{y}, \mathrm{t})$ is the intercept factor; $\mathrm{x}$, $\mathrm{y}$, and $\mathrm{t}$ are the symbols for co-ordinates and time.

The cosine factor is the incidence cosine between the incident sun ray and the normal to the heliostat 
surface. This factor can be calculated using the incident and reflected vectors, as follows:

$$
\cos =\cos [\arccos (\overrightarrow{\mathrm{S}} \cdot \overrightarrow{\mathrm{R}}) / 2]
$$

where $\overrightarrow{\mathrm{S}}$ is the incident vector and $\overrightarrow{\mathrm{R}}$ is the reflect vector.

The atmospheric attenuation factor, which can be considered as a function of the distance between the heliostat and the receiver, is used to calculate the beam losses of the reflected ray. It can be obtained in the following manner:

$$
\mathrm{f}_{\mathrm{at}}=\left\{\begin{array}{cc}
0.99321-0.0001176 \mathrm{~d}_{\mathrm{hr}}+1.97 \times 10^{-8} \mathrm{~d}_{\mathrm{hr}}^{2} & \mathrm{~d}_{\mathrm{hr}} \leq 1000 \mathrm{~m} \\
\exp \left(-0.0001106 \mathrm{~d}_{\mathrm{hr}}\right) & \mathrm{d}_{\mathrm{hr}}>1000 \mathrm{~m}
\end{array}\right.
$$

where $d_{h r}$ is the distance between the heliostat and the receiver (m).

The shadowing loss occurs when the incident rays are prevented by the neighboring heliostats before they reach the target heliostat. The blocking loss occurs when the reflected rays from the target heliostat are blocked by neighboring heliostats before reaching the receiver. The shadowing and blocking factor is defined as the fraction of the heliostat area free of shadowing and blocking over the entire area of the heliostat surface. The shadowing and blocking factor varies during the day because of the changing position of the sun. Additionally, this factor is influenced by the coordinates and orientations of neighboring heliostats. Therefore, the shadowing and blocking factor is the most complex factor that affects optical efficiency. The method used to calculate the shadowing and blocking factor in this study is introduced in Refs. [63-65]. In this method, the projected shape of the shadowing or blocking heliostat on the target heliostat is identical and parallel to the surface of the target heliostat. Given the radial staggered configuration, only three heliostats are checked for blocking: two in the next outer row and one in the outer second row. For shadowing, three shadowing heliostats and the aforementioned blocking heliostats are projected onto the target heliostat, i.e., six heliostats are checked for shadowing [64]. This method can save not only calculation time but can also ensure the accuracy of calculation results. 
The intercept factor is calculated using the HFLCAL model. The intercept factor can be calculated as follows:

$$
\mathrm{f}_{\mathrm{int}}=\frac{1}{2 \pi \sigma_{\mathrm{tot}}^{2}} \int_{\mathrm{x}^{\prime}} \int_{\mathrm{y}^{\prime}} \exp \left(-\frac{\mathrm{x}^{2}+\mathrm{y}^{\prime 2}}{2 \sigma_{\mathrm{tot}}^{2}}\right) d y^{\prime} d x^{\prime}
$$

where $\sigma_{\text {tot }}$ is the total standard deviation of the incident ray on the receiver; it includes four parts: the sun shape error $\left(\sigma_{\mathrm{sun}}\right)$, the beam quality error $\left(\sigma_{\mathrm{bp}}\right)$, the astigmatic error $\left(\sigma_{\mathrm{ast}}\right)$ and the tracking error $\left(\sigma_{t}\right)$. The total standard deviation can be calculated as follows:

$$
\sigma_{\mathrm{tot}}=\sqrt{\mathrm{d}_{\mathrm{hr}}^{2}\left(\sigma_{\mathrm{sun}}^{2}+\sigma_{\mathrm{bp}}^{2}+\sigma_{\mathrm{ast}}^{2}+\sigma_{\mathrm{t}}^{2}\right)}
$$

The astigmatic error can be calculated as follows:

$$
\sigma_{\mathrm{ast}}=\frac{\sqrt{0.5\left(\mathrm{H}_{\mathrm{t}}^{2}+\mathrm{W}_{\mathrm{s}}^{2}\right)}}{4 \mathrm{~d}_{\mathrm{hr}}}
$$

where, $\mathrm{H}_{\mathrm{t}}$ and $\mathrm{W}_{\mathrm{s}}$ are the imagined dimensions in the tangential and sagittal planes, respectively, at the distance $\mathrm{d}_{\mathrm{hr}}$ from the mirror (m). They are obtained using the following:

$$
\begin{gathered}
\mathrm{H}_{\mathrm{t}}=\mathrm{d}\left|\frac{\mathrm{d}_{\mathrm{hr}}}{\mathrm{f}}-\cos \omega\right| \\
\mathrm{W}_{\mathrm{s}}=\mathrm{d}\left|\frac{\mathrm{d}_{\mathrm{hr}}}{\mathrm{f}} \cos \omega-1\right|
\end{gathered}
$$

where $\mathrm{f}$ is the focal distance (m), which is equal to $\mathrm{d}_{\mathrm{hr}}$; $\mathrm{d}$ is the general dimension of the heliostat (m)

equal to the square root of the entire heliostat area.

$$
\mathrm{d}=\sqrt{\mathrm{LW} \times \mathrm{LH}}
$$

\section{References}

[1] Zhu Y, Zhai R, Peng H, Yang Y. Exergy destruction analysis of solar tower aided coal-fired power generation system using exergy and advanced exergetic methods. Applied Thermal Engineering. 2016;108:339-46.

[2] Li J, Yu X, Wang J, Huang S. Coupling performance analysis of a solar aided coal-fired power plant. Applied Thermal Engineering. 2016;106:613-24.

[3] Zhai R, Li C, Chen Y, Yang Y, Patchigolla K, Oakey JE. Life cycle assessment of solar aided coalfired power system with and without heat storage. Energy Conversion and Management. 2016;111:45365.

[4] Powell KM, Rashid K, Ellingwood K, Tuttle J, Iverson BD. Hybrid concentrated solar thermal power systems: A review. Renewable and Sustainable Energy Reviews. 2017;80:215-37. 
[5] Zhang M, Xu C, Du X, Amjad M, Wen D. Off-design performance of concentrated solar heat and coal double-source boiler power generation with thermocline energy storage. Applied Energy. 2017;189:697-710.

[6] Li J, Wu Z, Zeng K, Flamant G, Ding A, Wang J. Safety and efficiency assessment of a solar-aided coal-fired power plant. Energy Conversion and Management. 2017;150:714-24.

[7] Zoschak RJ, Wu SF. Studies of the direct input of solar energy to a fossil-fueled central station steam power plant. Solar Energy. 1975;17:297-305.

[8] Hu E, Yang Y, Nishimura A, Yilmaz F, Kouzani A. Solar thermal aided power generation. Applied Energy. 2010;87:2881-5.

[9] Yang Y, Yan Q, Zhai R, Kouzani A, Hu E. An efficient way to use medium-or-low temperature solar heat for power generation - integration into conventional power plant. Applied Thermal Engineering. 2011;31:157-62.

[10] Odeh S, Behnia M, Morrison G. Performance evaluation of solar thermal electric generation systems. Energy Conversion and Management. 2003;44:2425-43.

[11] Rech S, Lazzaretto A, Grigolon E. Optimum integration of concentrating solar technologies in a real coal-fired power plant for fuel saving. Energy Conversion and Management. 2018;178:299-310.

[12] Wu J, Hou H, Hu E, Yang Y. Performance improvement of coal-fired power generation system integrating solar to preheat feedwater and reheated steam. Solar Energy. 2018;163:461-70.

[13] Zhao Y, Hong H, Jin H. Mid and low-temperature solar-coal hybridization mechanism and validation. Energy. 2014;74:78-87.

[14] Reddy VS, Kaushik S, Tyagi S. Exergetic analysis of solar concentrator aided coal fired super critical thermal power plant (SACSCTPT). Clean Technologies and Environmental Policy. 2013;15:133-45.

[15] Popov D. An option for solar thermal repowering of fossil fuel fired power plants. Solar Energy. 2011;85:344-9.

[16] Pierce W, Gauché P, von Backström T, Brent AC, Tadros A. A comparison of solar aided power generation (SAPG) and stand-alone concentrating solar power (CSP): A South African case study. Applied Thermal Engineering. 2013;61:657-62.

[17] Bakos GC, Tsechelidou C. Solar aided power generation of a $300 \mathrm{MW}$ lignite fired power plant combined with line-focus parabolic trough collectors field. Renewable Energy. 2013;60:540-7.

[18] Hong-juan H, Zhen-yue Y, Yong-ping Y, Si C, Na L, Junjie W. Performance evaluation of solar aided feedwater heating of coal-fired power generation (SAFHCPG) system under different operating conditions. Applied Energy. 2013;112:710-8.

[19] Huang C, Hou H, Hu E, Liang M, Yang Y. Impact of power station capacities and sizes of solar field on the performance of solar aided power generation. Energy. 2017;139:667-79.

[20] Hong H, Peng S, Zhang H, Sun J, Jin H. Performance assessment of hybrid solar energy and coalfired power plant based on feed-water preheating. Energy. 2017;128:830-8.

[21] Peng S, Hong H, Wang Y, Wang Z, Jin H. Off-design thermodynamic performances on typical days of a 330MW solar aided coal-fired power plant in China. Applied Energy. 2014;130:500-9.

[22] Hou H, Wu J, Yang Y, Hu E, Chen S. Performance of a solar aided power plant in fuel saving mode. Applied Energy. 2015;160:873-81.

[23] Wu J, Hou H, Yang Y, Hu E. Annual performance of a solar aided coal-fired power generation system (SACPG) with various solar field areas and thermal energy storage capacity. Applied Energy. 2015;157:123-33.

[24] Wu J, Hou H, Yang Y. Annual economic performance of a solar-aided 600MW coal-fired power 
generation system under different tracking modes, aperture areas, and storage capacities. Applied Thermal Engineering. 2016;104:319-32.

[25] Zhang N, Hou H, Yu G, Hu E, Duan L, Zhao J. Simulated Performance Analysis of A Solar Aided Power Generation Plant in Fuel Saving Operation Mode. Energy. 2018.

[26] Qin J, Hu E, Nathan GJ, Chen L. Mixed mode operation for the Solar Aided Power Generation. Applied Thermal Engineering. 2018;139:177-86.

[27] Qin J, Hu E, Nathan GJ. Impact of the operation of non-displaced feedwater heaters on the performance of Solar Aided Power Generation plants. Energy Conversion and Management. 2017;135:18.

[28] Qin J, Hu E, Nathan GJ. The performance of a Solar Aided Power Generation plant with diverse “configuration-operation" combinations. Energy Conversion and Management. 2016;124:155-67.

[29] Zhai R, Peng P, Yang Y, Zhao M. Optimization study of integration strategies in solar aided coalfired power generation system. Renewable Energy. 2014;68:80-6.

[30] Zhai R, Zhao M, Li C, Peng P, Yang Y. Improved Optimization Study of Integration Strategies in Solar Aided Coal-Fired Power Generation System. International Journal of Photoenergy. 2015;2015:1-8. [31] Zhao Y, Hong H, Jin H. Optimization of the solar field size for the solar-coal hybrid system. Applied Energy. 2017;185:1162-72.

[32] Wang Y, Xu J, Chen Z, Cao H, Zhang B. Technical and economical optimization for a typical solar hybrid coal-fired power plant in China. Applied Thermal Engineering. 2017;115:549-57.

[33] Zhong W, Chen X, Zhou Y, Wu Y, López C. Optimization of a solar aided coal-fired combined heat and power plant based on changeable integrate mode under different solar irradiance. Solar Energy. 2017;150:437-46.

[34] Zhai R, Yang Y, Zhu Y, Chen D. The evaluation of solar contribution in solar aided coal-fired power plant. International Journal of Photoenergy. 2013;2013.

[35] Zhai R, Zhao M, Tan K, Yang Y. Optimizing operation of a solar-aided coal-fired power system based on the solar contribution evaluation method. Applied Energy. 2015;146:328-34.

[36] Zhai R, Liu H, Li C, Zhao M, Yang Y. Analysis of a solar-aided coal-fired power generation system based on thermo-economic structural theory. Energy. 2016;102:375-87.

[37] Wang R, Sun J, Hong H, Jin H. Comprehensive evaluation for different modes of solar-aided coalfired power generation system under common framework regarding both coal-savability and efficiencypromotability. Energy. 2018;143:151-67.

[38] Zhu Y, Zhai R, Zhao M, Yang Y, Yan Q. Evaluation methods of solar contribution in solar aided coal-fired power generation system. Energy conversion and management. 2015;102:209-16.

[39] Zhao Y, Hong H, Jin H, Li P. Thermodynamic mechanism for hybridization of moderate-temperature solar heat with conventional fossil-fired power plant. Energy. 2017;133:832-42.

[40] Suresh M, Reddy K, Kolar AK. 4-E (Energy, Exergy, Environment, and Economic) analysis of solar thermal aided coal-fired power plants. Energy for sustainable development. 2010;14:267-79.

[41] Adibhatla S, Kaushik SC. Energy, exergy, economic and environmental (4E) analyses of a conceptual solar aided coal fired 500 MWe thermal power plant with thermal energy storage option. Sustainable Energy Technologies and Assessments. 2017;21:89-99.

[42] Peng S, Wang Z, Hong H, Xu D, Jin H. Exergy evaluation of a typical 330MW solar-hybrid coalfired power plant in China. Energy Conversion and Management. 2014;85:848-55.

[43] Hou H, Xu Z, Yang Y. An evaluation method of solar contribution in a solar aided power generation (SAPG) system based on exergy analysis. Applied Energy. 2016;182:1-8. 
[44] Zhang M, Du X, Pang L, Xu C, Yang L. Performance of double source boiler with coal-fired and solar power tower heat for supercritical power generating unit. Energy. 2016;104:64-75.

[45] Li C, Yang Z, Zhai R, Yang Y, Patchigolla K, Oakey JE. Off-design thermodynamic performances of a solar tower aided coal-fired power plant for different solar multiples with thermal energy storage. Energy. 2018;163:956-68.

[46] Li C, Zhai R, Yang Y, Patchigolla K, Oakey JE. Thermal performance of different integration schemes for a solar tower aided coal-fired power system. Energy Conversion and Management. 2018;171:1237-45.

[47] Li C, Zhai R, Liu H, Yang Y, Wu H. Optimization of a heliostat field layout using hybrid PSO-GA algorithm. Applied Thermal Engineering. 2018;128:33-41.

[48] Li C, Zhai R, Yang Y. Optimization of a Heliostat Field Layout on Annual Basis Using a Hybrid Algorithm Combining Particle Swarm Optimization Algorithm and Genetic Algorithm. Energies. 2017;10:1924.

[49] Wagner MJ, Klein SA, Reindl DT. Simulation of utility-scale central receiver system power plants. ASME 2009 3rd International Conference on Energy Sustainability collocated with the Heat Transfer and InterPACK09 Conferences: American Society of Mechanical Engineers; 2009. p. 605-14.

[50] Che D. Boilers: theory, design and operation: Xi'an Jiaotong University Press; 2008.

[51] Zhu Y, Zhai R, Qi J, Yang Y, Reyes-Belmonte MA, Romero M, Yan Q. Annual performance of solar tower aided coal-fired power generation system. Energy. 2017;119:662-74.

[52] Short W, Packey DJ, Holt T. A manual for the economic evaluation of energy efficiency and renewable energy technologies: University Press of the Pacific; 1995.

[53] Nik AA, Nejad FM, Zakeri H. Hybrid PSO and GA approach for optimizing surveyed asphalt pavement inspection units in massive network. Automation in Construction. 2016;71:325-45.

[54] Yu S, Wei Y-M, Wang K. A PSO-GA optimal model to estimate primary energy demand of China. Energy Policy. 2012;42:329-40.

[55] Garg H. A hybrid PSO-GA algorithm for constrained optimization problems. Applied Mathematics and Computation. 2016;274:292-305.

[56] Mozafar MR, Moradi MH, Amini MH. A simultaneous approach for optimal allocation of renewable energy sources and electric vehicle charging stations in smart grids based on improved GA-PSO algorithm. Sustainable Cities and Society. 2017;32:627-37.

[57] Ghorbani N, Kasaeian A, Toopshekan A, Bahrami L, Maghami A. Optimizing a hybrid wind-PVbattery system using GA-PSO and MOPSO for reducing cost and increasing reliability. Energy. 2018;154:581-91.

[58] Collado FJ, Guallar J. Two-stages optimised design of the collector field of solar power tower plants. Solar Energy. 2016;135:884-96.

[59] Collado FJ, Guallar J. A review of optimized design layouts for solar power tower plants with campo code. Renewable and Sustainable Energy Reviews. 2013;20:142-54.

[60] Kolb GJ, Ho CK, Mancini TR, Gary JA. Power tower technology roadmap and cost reduction plan. Sandia National Laboratories, Albuquerque, NM, Report No SAND2011-2419. 2011.

[61] Zhu Y, Zhai R, Yang Y, Reyes-Belmonte M. Techno-Economic Analysis of Solar Tower Aided CoalFired Power Generation System. Energies. 2017;10:1392.

[62] Saghafifar M, Gadalla M. Thermo-economic analysis of air bottoming cycle hybridization using heliostat field collector: A comparative analysis. Energy. 2016;112:698-714.

[63] Collado FJ. Design of solar tower plants heliostat by heliostat: the shadowing and blocking factor. 
2009.

[64] Collado FJ, Guallar J. Campo: Generation of regular heliostat fields. Renewable Energy. 2012;46:49-59.

[65] Sassi G. Some notes on shadow and blockage effects. Solar Energy. 1983;31:331-3. 